\title{
MATERIAL CONSTRUCTIVO LATERICIO PROCEDENTE DEL CAMPAMENTO DE LA LEGIO VII GEMINA EN LEÓN. LA INTERVENCIÓN ARQUEOLÓGICA DE PUERTA OBISPO
}

\author{
BUILDING MATERIAL (BRICKS AND TILES) FROM THE CAMP OF THE LEGIO VII GEMINA IN LEÓN. \\ THE ARCHAEOLOGICAL INTERVENTION IN PUERTA OBISPO
}

\author{
ÁNGEL MORILLO \\ Universidad Complutense
}

JAVIER SALIDO DOMÍNGUEZ

Escuela Española de Historia y Arqueología en Roma - CSIC

\section{INTRODUCCIÓN ${ }^{1}$}

El material constructivo latericio (ladrillos, tejas) es uno de los elementos más comunes en cualquier excavación de época romana, siendo especialmente abundante en contextos urbanos y en acantonamientos militares. Uno de los rasgos más característicos de este material es su estandarización, ya que se fabrica en determinadas formas y tamaños acordes con su empleo posterior, que pueden variar levemente de una región a otra y entre uno y otro momento. El uso de módulos estandarizados permite identificar desde el punto de vista funcional cada uno de los elementos y su procedencia concreta, además de precisar la estratigrafía horizontal del edificio y determinar fases constructivas (Fernández Ochoa et alii, 1999, 299). Además, el material latericio, que con frecuencia aparece con marcas de fábrica, proporciona una información muy valiosa sobre aspectos productivos y comerciales.

Vitrubio menciona en varios pasajes tanto el adobe o later crudus como el ladrillo cocido o later coctus (De Arch. I, 5; II, 3; II, 8). La arqueología confirma que este material era empleado abundantemente en Roma durante el reinado de Augusto. Los estudios sobre técnicas constructivas realizados a partir de los años '90 del siglo XX han confirmado que en Hispania el ladrillo aparece esporádicamente en ámbitos como Ampurias en el siglo II a. C., haciéndose más frecuente conforme avanzaba el siglo I a. C. en la Bética (Roldán, 1995; Bendala y Roldán, 1999, 106) y

1. El presente trabajo se ha elaborado en el marco del Proyecto de I+D HAR2011-24095: Campamentos y territorios militares en Hispania, concedido por el Ministerio de Ciencia e Innovación el 1 de enero de 2012, así como del convenio de investigación: Los campamentos romanos de las legiones VI victrix y VII gemina en León. Estudio del material arqueológico procedente de las excavaciones arqueológicas en la ciudad de León, en el marco del Plan PAHIS 2004-2012 del Patrimonio Histórico de Castilla y León, ambos bajo la dirección de A. Morillo. generalizándose a partir de las primeras décadas de la siguiente centuria. En ciudades como Emerita $\mathrm{Au}$ gusta se utiliza abundantemente para paredes (opus testaceum) desde el reinado de Tiberio (Durán, 1999), si bien recientemente se ha adelantado al periodo augusteo su empleo en obras públicas (Pizzo, 2010). A partir de mediados del siglo I su empleo se generaliza, aunque en determinadas regiones, ajenas a este tipo de material por tradición cultural o por ausencia de arcillas adecuadas, queda circunscrito a las estancias calefactadas de los edificios termales, allí donde era estrictamente necesario (Roldán, 2008, 752). Dichas instalaciones se generalizan en suelo hispano a partir de las últimas décadas del siglo I d. C. (Fernández Ochoa et alii, 1999, 302).

Por lo que se refiere a las tejas para cubiertas, planas (tegulae) y curvas (imbrices), también se van a generalizar a lo largo del siglo I d. C. en la Hispania romana (Bermúdez, 1985), si bien se documentan anteriormente en zonas como la Bética y el ámbito mediterráneo, más en contacto con las influencias itálicas (Bendala y Roldán, 1999, 106). Aunque no se han publicado con detalle contextos augusteos y julioclaudios, en ámbitos como la Meseta y el norte peninsular dichos materiales latericios para techumbres parecen no ser demasiado habituales hasta el periodo flavio, si bien en acantonamientos militares debió introducirse la costumbre antes que en contextos civiles. En el campamento de la Legión IIII Macedónica en Herrera de Pisuerga se documentan tégulas asociadas a un horno amortizado en época de Claudio, probablemente empleado para cocer material latericio (Pérez González, 1989, 243-259). Por el momento en León no conocemos nada similar, aunque se han constatado restos latericios sin marca de taller en los registros arqueológicos de mediados del siglo I d. C, correspondientes a la legio VI victrix.

En el ámbito de la antigua Hispania, aunque se han realizado trabajos muy interesantes sobre este asunto, aún resultan escasos para tener un conocimiento general sobre el empleo de material latericio en la 


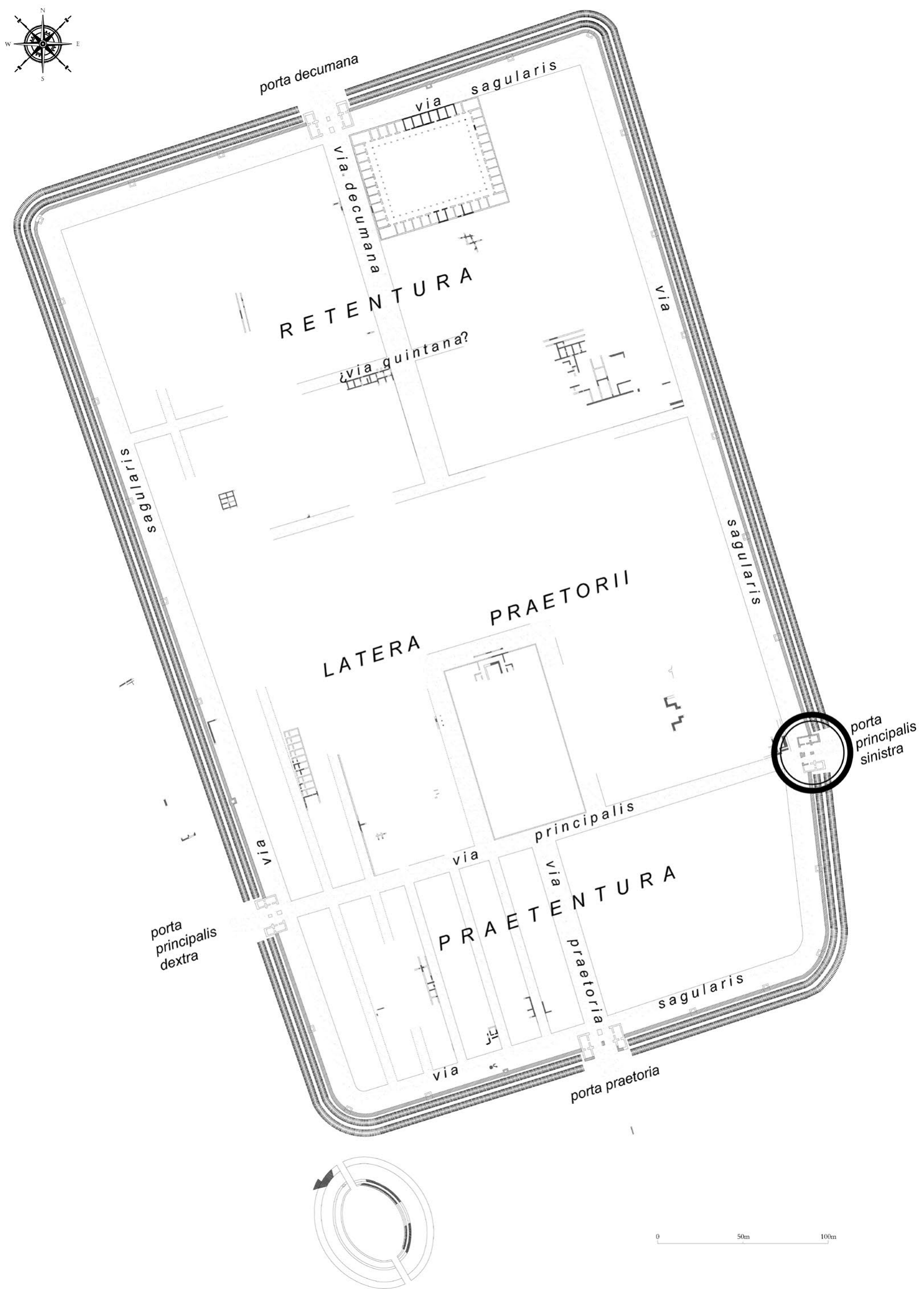

Figura 1: Planta del trazado hipotético del campamento de la legio VII gemina en León con indicación de la situación de Puerta Obispo (según A. Morillo y V. García Marcos, a partir de los datos de los informes de excavación proporcionados por la Dirección General de Patrimonio de la Junta de Castilla y León). 


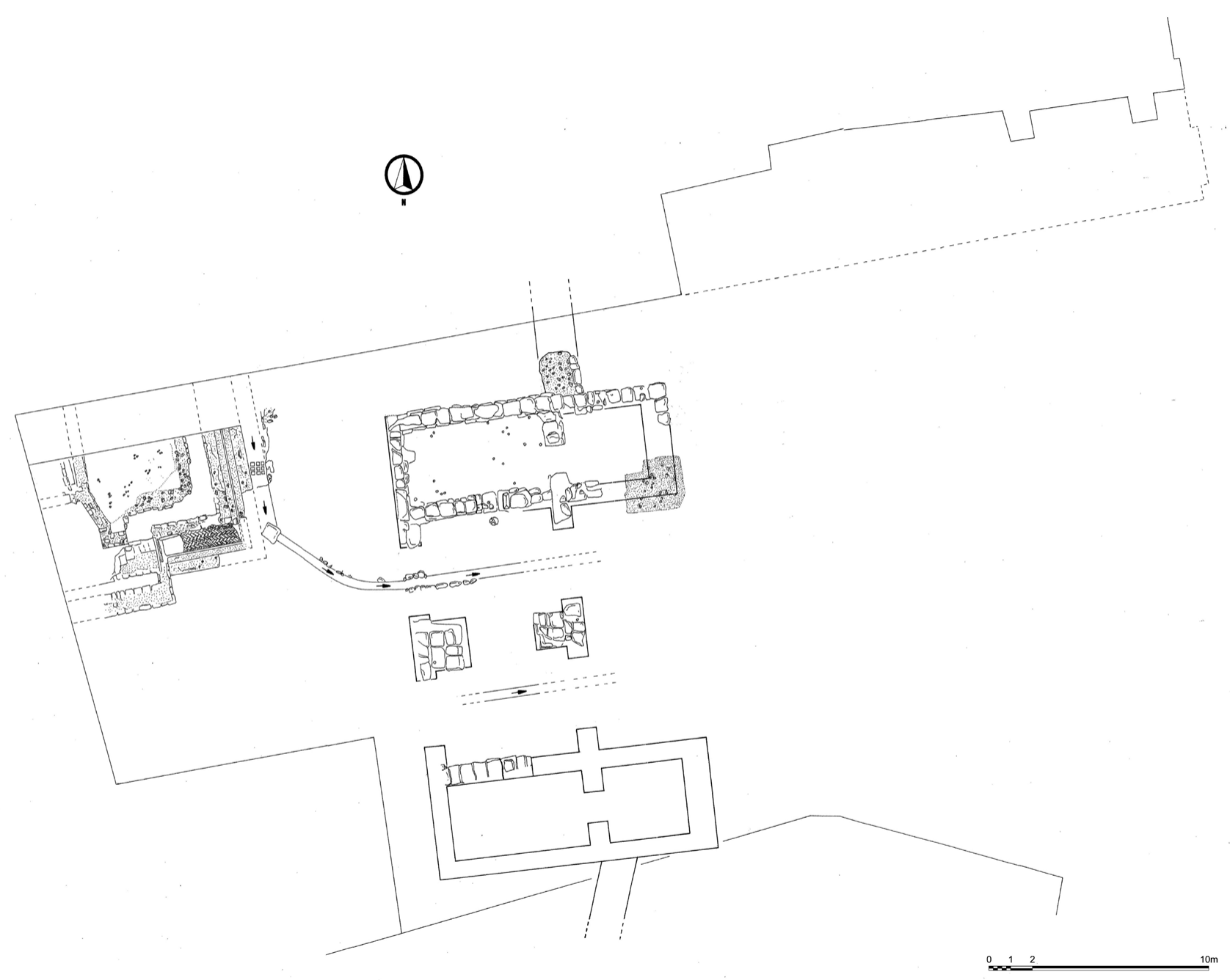

Figura 2: Planimetría de los restos altoimperiales de Puerta Obispo (García Marcos, 1996).

arquitectura hispanorromana, que permitan determinar tipos, sistemas constructivos, variedad y ritmos cronológicos de implantación y utilización (cf. Roldán Gómez, 2008, con bibliografía). Especial interés han despertado aspectos como el material de edificios termales y la identificación de talleres productivos o ámbitos de dispersión a partir de las marcas y sellos impresos sobre tejas y ladrillos romanos. Sin embargo, casi no se han abordado análisis integrales de material latericio de yacimientos concretos que comprendan tanto los ejemplares con marca de taller como aquellos anepígrafos. Uno de los ejemplos más recientes en este sentido, que presenta notables paralelos con León, es el del material del fuerte de la cohors I Celtiberorum en A Cidadela (A Coruña) (Carlsson-Brandt, 2011). Por su inserción dentro de contextos de fabricación y su estudio tipológico integral, revisten también especial interés los estudios del material latericio de los alfares de L'Almadrava, cerca de Denia (Gisbert, 1999), Los Matagallanes (Salobreña, Granada) (Torrecilla, 1998) y La Venta del Carmen (Los Barrios, Cádiz) (Redondo y Borge, 1998).

\section{EL CAMPAMENTO DE LEÓN Y SU MATERIAL LATERICIO}

El asentamiento militar de León, fundado en torno al cambio de Era por la legio VI victrix, estuvo ocupado hasta el $68 \mathrm{~d}$. C. por la mencionada unidad, que estableció dos campamentos sucesivos en el mismo lugar. Hacia el año 74 d. C. se construyen unos nuevos castra sobre el recinto anterior, en este caso pertenecientes a la legio VII gemina, unidad que permanecerá aquí hasta finales del siglo IV (García Marcos, 2002; Morillo y García Marcos, 2003 y 2006; Morillo, 2012, e. p.) (Fig. 1).

La presencia de abundante material latericio en León con estampillas de la legio VII gemina es algo perfectamente conocido. García y Bellido fue el primero en elaborar un catálogo de los diferentes tipos de marca de la mencionada legión, procedentes en su mayoría de la capital leonesa, en torno a la cual se encontraban sin duda focalizados los centros productores (García y Bellido, 1970, 588-599). Años más tarde se publicó un posible taller alfarero de la legio 
VII gemina en Candanedo y Rabanal de Fenar (González, 1981; Gutiérrez González, 1985, 156-159), a casi $30 \mathrm{~km}$ de la ciudad. Le Roux vuelve a abordar esta cuestión dentro de un trabajo general sobre marcas militares hispanas (Le Roux, 1999). Desde entonces se han dado a conocer algunos materiales procedentes de excavaciones, como los de la necrópolis del Campo de Vegazana (Liz y Amaré, 1993), el monasterio de San Claudio (González, 1994), la calle San Salvador del Nido (Fernández Freile, 2003), el acueducto (Campomanes, 2006) o el polígono de La Palomera (Amaré y Álvarez Vega, 2006). El reciente análisis de Kurzmann sobre material latericio con estampilla militar se ha ocupado también de los sellos de la VII Gémina (2006, 99-104), aunque su bibliografía presenta ausencias muy significativas.
La atención preferente se ha dedicado al análisis de los sellos militares, mientras que aspectos relativos a la fabricación y empleo del material latericio sobre el que aparecían las marcas se ha dejado en un segundo plano, así como su posición dentro de los registros cronoestratigráficos.

Las excavaciones desarrolladas durante el año 1996 bajo la dirección de V. García Marcos en el sector de Puerta Obispo ${ }^{2}$, situado al este de la ciudad, justo encima de la antigua porta principalis sinistra del campamento romano y de las letrinas de las antiguas grandes termas legionarias que se encuentran bajo la Catedral (García Marcos et alii, 2004; Morillo y García Marcos, 2005) proporcionaron un volumen considerable de material latericio, que presentamos a continuación (Fig. 2).

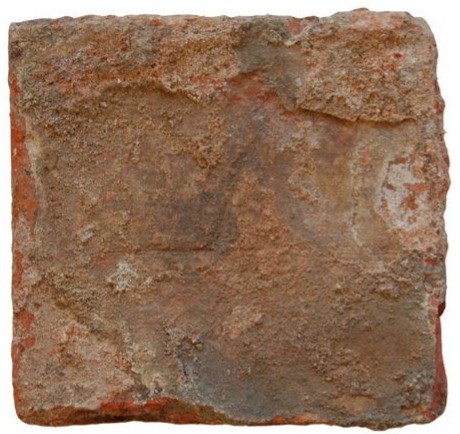

1
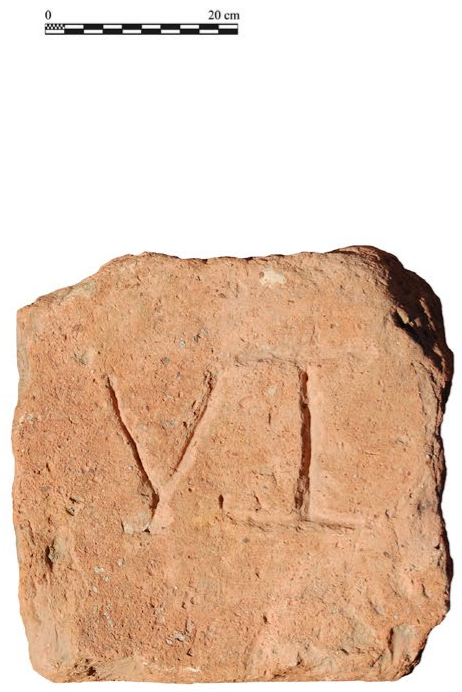

4



2

Figura 3: Ladrillos bessales ( $\left.\mathrm{n}^{\circ} 1-3\right)$.

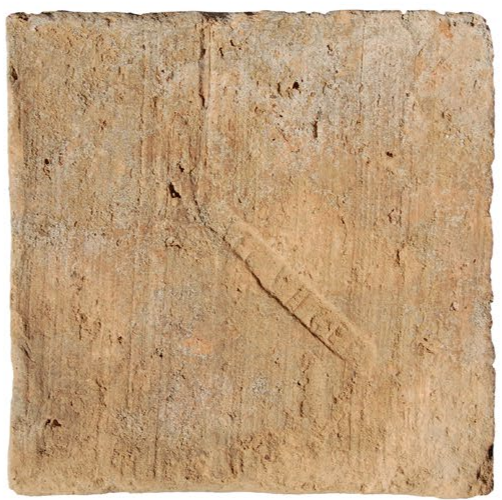

5

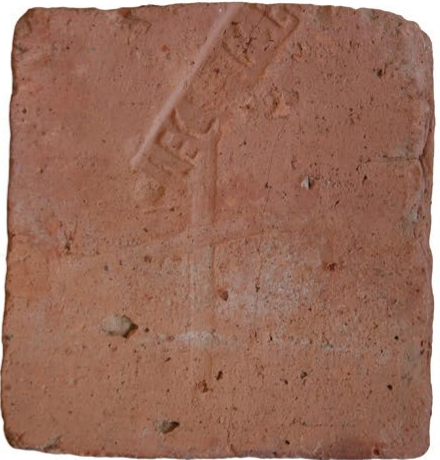

3

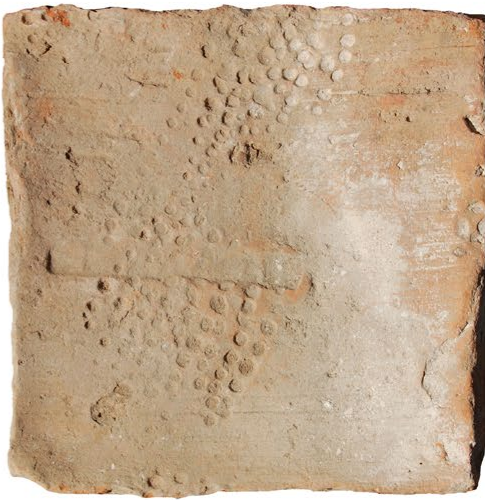

6

Figura 4: Ladrillos pedales ( $\mathrm{n}^{\circ} 4-6$ ).

2. Agradecemos a V. García Marcos, Arqueólogo Municipal de León y director de la mencionada excavación, el acceso al material y los datos relativos a la misma. 


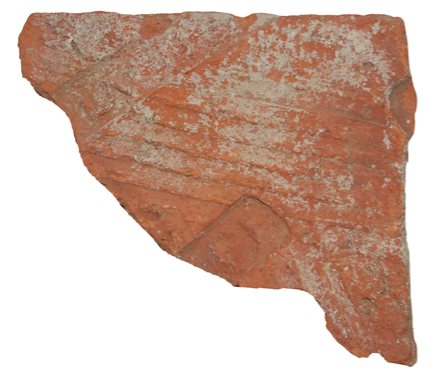

7



9

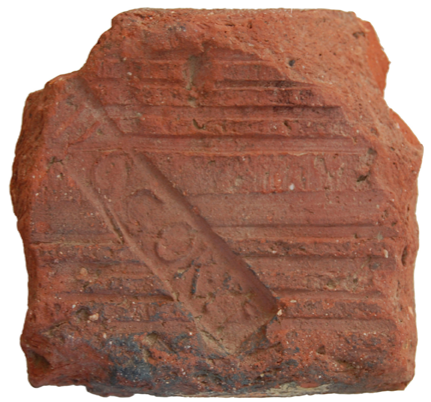

8

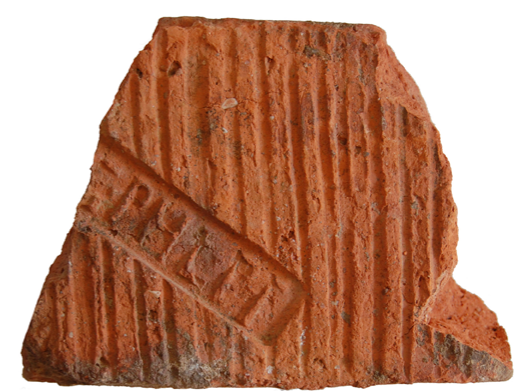

10

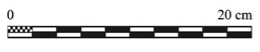

Figura 5: Ladrillos de tipo indeterminado ( $\left.\mathrm{n}^{\circ} 7-10\right)$.

\section{CATÁLOGO DE MATERIAL CONSTRUCTIVO LATERICIO}

\section{ELEMENTOS DE SUSTENTACIÓN}

\section{Ladrillos bessales}

1. $\quad \mathrm{N}^{\mathrm{o}}$ inv. 2004/20/5/CN/01 (Fig. 3) Ladrillo completo de tipo bessal Dimensiones: 18,7 x $18,5 \times 7 \mathrm{~cm}$

2. $\quad N^{o}$ inv. $2004 / 20 / 5 / C N / 08$ (Fig. 3) Ladrillo completo de tipo bessal Dimensiones: 19 x 18,5 x 6, $5 \mathrm{~cm}$

3. $\quad \mathrm{N}^{\mathrm{o}}$ inv. $2004 / 20 / 5 / \mathrm{CN} / 09$ (Figs. 3 y 13 ) Ladrillo completo de tipo bessal. Presenta una marca de producción digital en forma de aspa. Dimensiones: $23 \times 22 \times 6 \mathrm{~cm}$ Dimensiones de la cartela: 3 x [11] cm Sello: Leg(io) VII Ge(mina), dispuesta en una cartela en forma de tabula ansata. En el texto destaca el menor relieve del numeral.

Ladrillos pedales

4. $\quad \mathrm{N}^{\mathrm{o}}$ inv. 2004/20/02 (Fig. 4)

Ladrillo completo de tipo pedal.

Dimensiones: $25,5 \times 25 \times 9 \mathrm{~cm}$

Dimensiones del numeral: 10, 5 x $16 \mathrm{~cm}$

Sello: VI. Este numeral aparece inciso a mano alzada.
5. $\quad \mathrm{N}^{\mathrm{o}}$ inv. $2004 / 20 / 03$ (Fig. 4)

Ladrillo completo de tipo pedal.

Dimensiones: 30 × 29, 5 × $7 \mathrm{~cm}$

Dimensiones de la cartela: 2 x [12] cm

Sello: Leg(io) VII Gem(ina) en cartela rectangular con extremos redondeados.

6. $\quad \mathrm{N}^{\mathrm{o}}$ inv. 2004/20/1115/19; Área 1000 (Puerta); UE 1115 (Fig. 4)

Ladrillo completo de tipo pedal. Presenta una huella casi completa de una sandalia

claveteada o caligae, y otras dos parciales, dos de ellas superpuestas. Además se observa parte de una huella de cánido (canis familiaris).

Dimensiones: $29 \times 28 \times 6 \mathrm{~cm}$

Ladrillos de tipo indeterminado

7. $\mathrm{N}^{\mathrm{o}}$ inv. 2004/20/1101/25; Área 1000 (Puerta); UE 1101 (Figs. 5 y 15)

Ladrillo de tipo indeterminado con superficie estriada.

Dimensiones: 17 × $15 \times 7 \mathrm{~cm}$

Dimensiones de las cartelas: 2, 2 x [10] $\mathrm{cm} ; 2$, $5 \times[4,5] \mathrm{cm}$

Sellos: En la parte superior, en cartela rectangular: L(egio) VII G(emina); en otra cartela rectangular [Legio VII Gemina] P(ia) F(elix)

8. $\quad \mathrm{N}^{\mathrm{o}}$ inv. 2004/20/4004/01; Área 4000 (Termas); UE 4004 (Fig. 5) 
Ladrillo de tipo indeterminado con superficie estriada.

Dimensiones: 16 x 14 x $6 \mathrm{~cm}$

Dimensiones de la cartela: $3 \times$ [12] $\mathrm{cm}$

Sello: [Legio V]II G(emina) Gor(diana) P(ia)

$\mathrm{F}$ (elix) en cartela rectangular.

9. $\quad \mathrm{N}^{\mathrm{o}}$ inv. 2004/20/4014/13; Área 4000 (Termas);

UE 4014 (Fig. 5)

Ladrillo de tipo indeterminado con superficie estriada.

Dimensiones: 17 x $11 \times 7 \mathrm{~cm}$

Dimensiones de la cartela: $2,5 \times 8 \mathrm{~cm}$

Sello: [Legio VII Gemina] Max(iminiana) P(ia)

[Felix] en cartela rectangular.

10. $\mathrm{N}^{\mathrm{o}}$ inv. 2004/20/5009/19; Área 5000 (Termas);

UE 5009 (Figs. 5 y 20)

Ladrillo de tipo indeterminado con superficie estriada.

Dimensiones: 20 x 14, 5 x $7 \mathrm{~cm}$

Dimensiones de la cartela: 3,4 x $10 \mathrm{~cm}$

Sello: [Legio VII] G(emina) Phil(ippiana) P(ia)

$\mathrm{F}$ (elix) en cartela rectangular. Hay un nexo $\mathrm{L} e$ I.

Ladrillos semicirculares y en cuarto de círculo

11. $\mathrm{N}^{\mathrm{o}}$ inv. 2004/20/4014/15; Área 4000 (Termas);

UE 4014 (Fig. 6)

Dimensiones: 19 × 9 × $8,5 \mathrm{~cm}$

Ladrillos en cuarto de círculo

12. $\mathrm{N}^{\mathrm{o}}$ inv. $2004 / 20 / 5 / \mathrm{CN} / 03$ (Fig. 6 )

Dimensiones: $15,5 \times 14,5 \times 6 \mathrm{~cm}$

13. $\quad \mathrm{N}^{\mathrm{o}}$ inv. $2004 / 20 / 5 / \mathrm{CN} / 04$ (Fig. 6 )

Dimensiones: 15,8 x 15,5 x $5,7 \mathrm{~cm}$

14. $\mathrm{N}^{\mathrm{o}}$ inv. $2004 / 20 / 5 / \mathrm{CN} / 05$ (Fig. 6 )

Dimensiones: 16,8 × 16 × $6 \mathrm{~cm}$

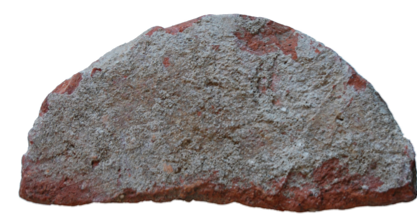

11

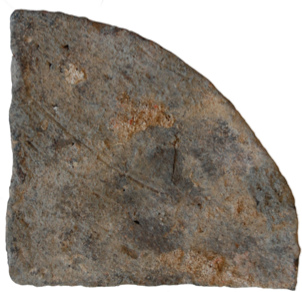

14

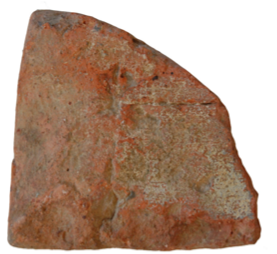

12

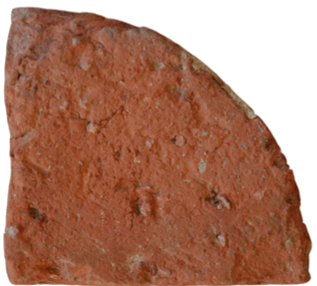

15
15. $\quad \mathrm{N}^{\mathrm{o}}$ inv. $2004 / 20 / 5 / \mathrm{CN} / 06$ (Fig. 6 )

Dimensiones: $20 \times 19 \times 7,3 \mathrm{~cm}$

16. $\quad \mathrm{N}^{\circ}$ inv. 2004/20/1071/42; Área 5000

(Termas); UE 1071 (Fig. 6)

Dimensiones: 15 x 15 x $5,5 \mathrm{~cm}$

Ladrillos en octavo de círculo

17. $\mathrm{N}^{\circ}$ inv. 2004/20/5/CN/02 (Fig. 6)

Dimensiones: 15 x 14 x $7 \mathrm{~cm}$

ELEMENTOS PARA CONCAMERATIONES

Tegulae mammatae

18. $\quad \mathrm{N}^{\mathrm{o}}$ inv. 2004/20/1105/09; Área 1000; UE 1105

(Fig. 7)

Fragmento de tegula mammata con apéndice troncopiramidal.

Dimensiones: $16 \times 10 \times 3 \mathrm{~cm}$

19. $\mathrm{N}^{\mathrm{o}}$ inv. 2004/20/4014/15; Área 4000 (Termas); UE 4014 (Fig. 7)

Apéndice troncopiramidal perteneciente a una tegula mammata.

Dimensiones: $5,5 \times 5 \times 4 \mathrm{~cm}$

20. $\mathrm{N}^{\circ}$ inv. 2004/20/5019/08; Área 5000 (Termas); UE 5019 (Fig. 7)

Fragmento de tegula mammata, con protuberancia circular en la cara exterior. La superficie interior se encuentra estriada.

Dimensiones: 17,5 x 12, 3 × $3 \mathrm{~cm}$

Tubuli latericii

21-34. $\mathrm{N}^{\circ}$ inv. 2004/20/4021/22-35; Área 4000 (Termas); UE 4021 (Fig. 8)

Catorce fragmentos de diferentes dimensiones pertenecientes a tubuli latericii.

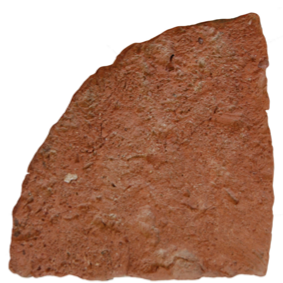

13
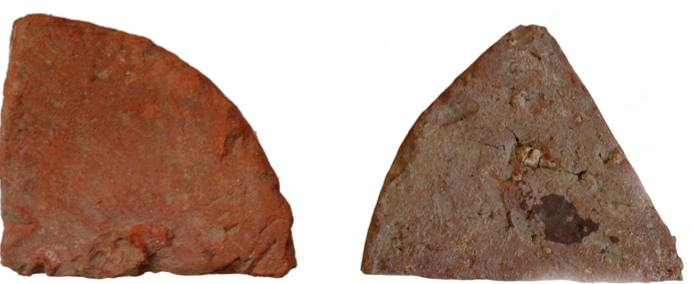

16

Figura 6: Ladrillo semicircular ( $\left.{ }^{\circ} 11\right)$, en cuarto de círculo $\left(\mathrm{n}^{\mathrm{o}} 12-16\right)$ y en octavo de círculo $\left(\mathrm{n}^{\mathrm{o}} 17\right)$. 


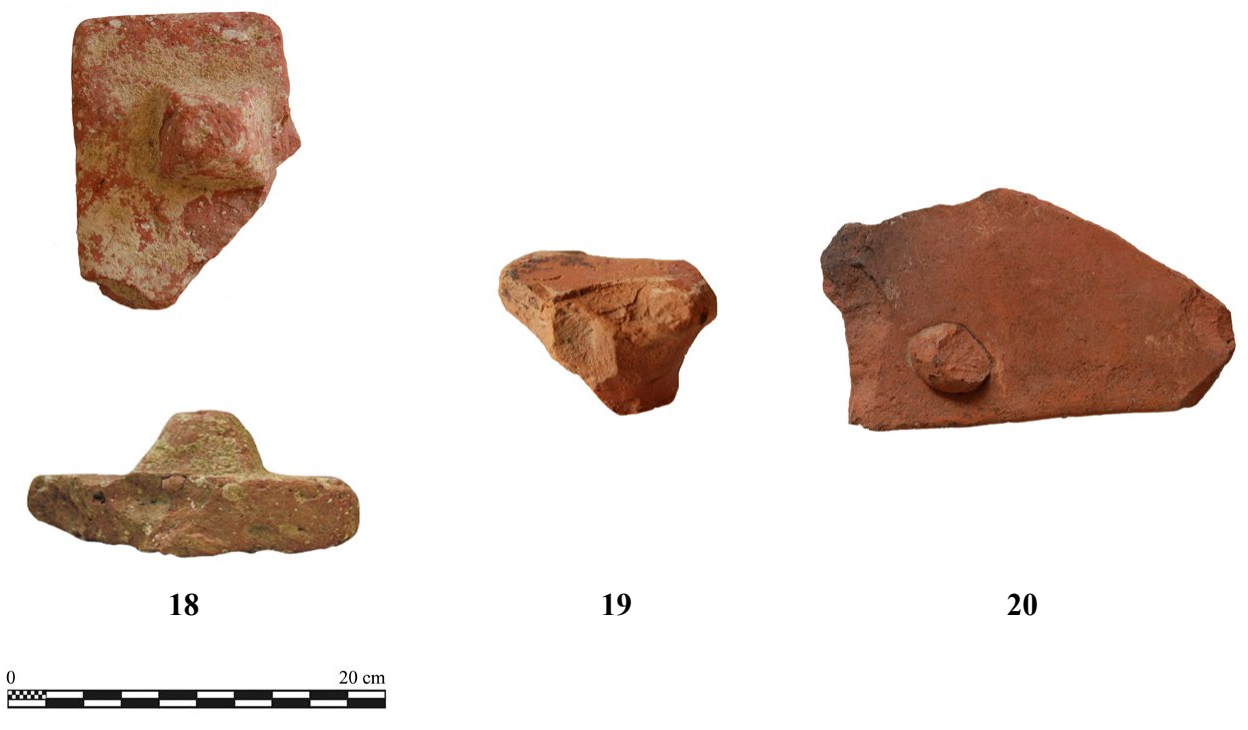

Figura 7: Tegulae mammatae $\left(\mathrm{n}^{\circ} 18-20\right)$.

\section{ELEMENTOS PARA CUBIERTAS}

\section{Tegulae}

35. $\quad N^{o}$ inv. 2004/20/01 (Fig. 9 y 13)

Fragmento de tegula con estriado en la parte posterior para ser adherida a otra superficie. Presenta una marca de producción practicada con tres dedos de forma ondulada.

Dimensiones: 26 × 16 × 3, $5 \mathrm{~cm}$

Dimensiones de la cartela: 3 x $9 \mathrm{~cm}$

Altura de las letras: $2 \mathrm{~cm}$

Sello: L(egio) VII G(emina) [...] en cartela rectangular

36. $\quad \mathrm{N}^{\mathrm{o}}$ inv. 2004/20/03 (Fig. 9 y 14)

Fragmento de tegula

Dimensiones: [19] x [14] x $2 \mathrm{~cm}$

Dimensiones de la cartela: 3 x 8,5 cm

Altura de las letras: $2 \mathrm{~cm}$

Sello: L(egio) VII G(emina) F(elix) en cartela rectangular. Nexo en el numeral. El punzón empleado, muy peculiar, no se ha documentado hasta el momento.

37. No inv. 2004/20/5/CN/07 (Fig. 9)

Pequeño fragmento de tegula

Dimensiones: $15 \times 12 \times 3 \mathrm{~cm}$

Presenta una huella de cánido de 4 x $4 \mathrm{~cm}$

38. $\quad N^{o}$ inv. 2004/20/05 (Fig. 9)

Fragmento de tegula

Dimensiones: $18 \times 9 \times 3,5 \mathrm{~cm}$

Presenta una huella de cánido de $5 \times 5 \mathrm{~cm}$

39. $\quad N^{o}$ inv. 2004/20/06 (Fig. 9)

Fragmento de tegula, estriada por su parte interna

Dimensiones: 11,5 x 11 x 2, $5 \mathrm{~cm}$

Dimensiones de la cartela: $2,8 \times 11 \mathrm{~cm}$

Sello: [Legio VI]I G(emina) Gor(diana) P(ia)

$\mathrm{F}$ (elix) en cartela rectangular.
40. $N^{o}$ inv. 2004/20/1014/37; Área 1000 (Puerta); UE 1014 (Fig. 9)

Fragmento de tegula, estriada por su parte interna

Dimensiones: 13,5 x 11, 5 × $3 \mathrm{~cm}$

Dimensiones de la cartela: $2,8 \times 6,7 \mathrm{~cm}$

Sello: L(egio) VII [Gemina ....] en cartela rectangular

41. $\mathrm{N}^{\mathrm{o}}$ inv. 2004/20/1020/04; Área 1000 (Puerta); UE 1020 (Figs. 9 y 15)

Fragmento de tegula

Dimensiones: $22 \times 12 \times 3 \mathrm{~cm}$

Dimensiones de la cartela: $2,8 \times[11] \mathrm{cm}$

Sello: L(egio) VII G(emina) P(ia) [...] en cartela rectangular. Presenta un relieve muy bajo.

42. $\mathrm{N}^{\mathrm{o}}$ inv. 2004/20/1020/05; Área 1000 (Puerta); UE 1020 (Fig. 9)

Fragmento de tegula

Dimensiones: $19 \times 15 \times 3 \mathrm{~cm}$

Dimensiones de la cartela: 2 x [11] cm

Sello: L(egio) VII Ge(mina) en cartela rectangular. Presenta un relieve muy bajo.

43. $\mathrm{N}^{\mathrm{o}}$ inv. 2004/20/1020/06; Área 1000 (Puerta); UE 1020 (Figs. 9 y 16)

Fragmento de tegula con superficie estriada. Presenta una marca de producción circular.

Dimensiones: $24 \times 13 \times 3 \mathrm{~cm}$

Dimensiones de la cartela: $3 \times$ [6] cm

Sello: [Legio VII] G(emina) P(ia) F(elix) en cartela rectangular.

44. $\quad \mathrm{N}^{\mathrm{o}}$ inv. 2004/20/1020/07; Área 1000 (Puerta); UE 1020 (Fig. 9)

Fragmento de tegula

Dimensiones: $22 \times 22 \times 3 \mathrm{~cm}$

Sello: L(egio) VII [...]

45. $\mathrm{N}^{\mathrm{o}}$ inv. 2004/20/1021/17; Área 1000 (Puerta); UE 1021 (Figs. 9 y 19) 
Fragmento de tegula

Dimensiones: $6,5 \times 6 \times 3 \mathrm{~cm}$

Dimensiones de la cartela: $2,8 \times[6,5] \mathrm{cm}$

Sello: [Legio VII Gemina] Gor(diana) P(ia)

$\mathrm{F}$ (elix) en cartela rectangular.

46. $\quad \mathrm{N}^{\mathrm{o}}$ inv. 2004/20/1021/18; Área 1000 (Puerta); UE 1021 (Fig. 9)

Fragmento de tegula, estriada por su parte interna

Dimensiones: $12,5 \times 12 \times 3 \mathrm{~cm}$

Dimensiones de la cartela: 3 x $[5,5] \mathrm{cm}$

Sello: L(egio) VII [...]

47. $\mathrm{N}^{\mathrm{o}}$ inv. 2004/20/1021/19; Área 1000 (Puerta); UE 1021 (Fig. 9)

Fragmento de tegula, estriada por su parte interna

Dimensiones: $8 \times 6 \times 2,5 \mathrm{~cm}$

Dimensiones de la cartela: $2,8 \times[4,8] \mathrm{cm}$

Sello: L(egio) VI[I ...]

48. $\mathrm{N}^{\mathrm{o}}$ inv. 2004/20/1021/20; Área 1000 (Puerta); UE 1021 (Figs. 9 y 19)

Fragmento de tegula, estriada por su parte interna

Dimensiones: 9 x 7, 5 × 3, $3 \mathrm{~cm}$

Dimensiones de la cartela: $2,8 \times[6] \mathrm{cm}$

Sello: [Legio VII Gemina] Gor(diana) P(ia)

[Felix] en cartela rectangular.

49. $\quad N^{0}$ inv. 2004/20/1021/21; Área 1000 (Puerta); UE 1021 (Figs. 9 y 20)

Fragmento de tegula, estriada por su parte interna
Dimensiones: 12 × 8 × $3 \mathrm{~cm}$

Dimensiones de la cartela: 3 x [12] cm

Sello: [Legio V]II G(emina) Phıl(ippiana) P(ia)

$\mathrm{F}$ (elix) en cartela rectangular.

50. $\quad \mathrm{N}^{\mathrm{o}}$ inv. 2004/20/1032/13; Área 1000 (Puerta);

UE 1032 (Figs. 9 y 19)

Fragmento de tegula

Dimensiones: 12 x $11 \times 3,3 \mathrm{~cm}$

Dimensiones de la cartela: $2,8 \times$ [5] $\mathrm{cm}$

Sello: [Legio VII Gemina G]or(diana) P(ia)

$\mathrm{F}$ (elix) en cartela rectangular.

51. $\quad \mathrm{N}^{\circ}$ inv. 2004/20/1032/14; Área 1000 (Puerta); UE 1032 (Fig. 9)

Fragmento de tegula

Dimensiones: 7 × 6, 5 × 1, $5 \mathrm{~cm}$

Dimensiones de la cartela: $2,8 \times$ [7] $\mathrm{cm}$

Sello: [Legio VII Gemina] Phil(ippiana) [Pia

Felix] en cartela rectangular.

52. $\quad \mathrm{N}^{\circ}$ inv. 2004/20/1043/08; Área 1000 (Puerta); UE 1043 (Fig. 9)

Fragmento de tegula

Dimensiones: $10 \times 6 \times 3 \mathrm{~cm}$

Dimensiones de la cartela: $2,5 \times$ x [3] cm

Sello: Leg(io) V(II) [Gemina ...] en cartela rectangular.

53. $\quad \mathrm{N}^{\circ}$ inv. 2004/20/1071/33; Área 1000 (Puerta); UE 1071 (Fig. 9)

Fragmento de tegula con superficie estriada

Dimensiones: $28 \times 15 \times 3 \mathrm{~cm}$

54. $\quad \mathrm{N}^{\mathrm{o}}$ inv. 2004/20/1071/33G; Área 1000 (Puerta); UE 1071 (Figs. 9 y 18)

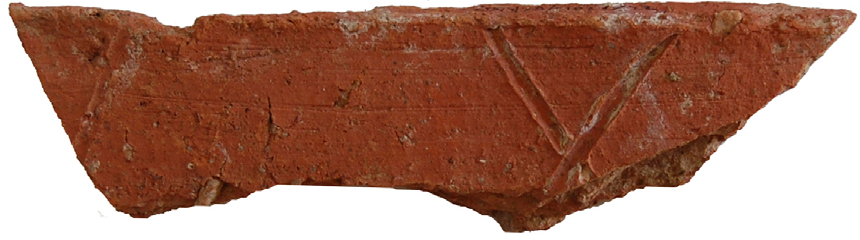

21

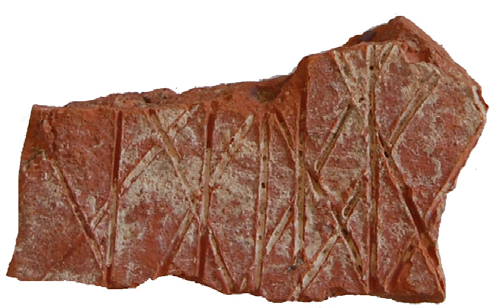

23

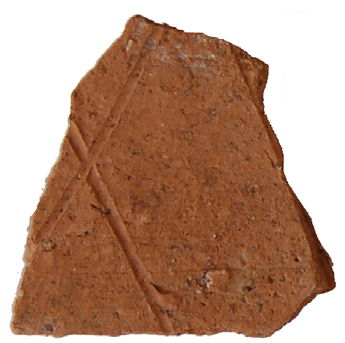

22

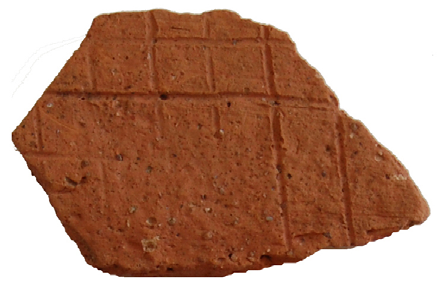

25

0

$20 \mathrm{~cm}$

Figura 8: Tubuli latericii $\left(\mathrm{n}^{\circ} 21-25\right)$. 
Fragmento de tegula con superficie estriada Dimensiones: [22] x [13, 5] x 2,5 cm

Dimensiones de la cartela: 2 x $10,5 \mathrm{~cm}$ Sello: L(egio) VII G(emina) Max(iminiana) $[\mathrm{p}(\mathrm{ia}) \mathrm{f}(\mathrm{elix})]$ en cartela rectangular.
55. $\mathrm{N}^{\mathrm{o}}$ inv. 2004/20/1071/34; Área 1000 (Puerta); UE 1071 (Figs. 10 y 13)

Fragmento de tegula con superficie estriada Dimensiones: $16 \times 12 \times 3 \mathrm{~cm}$ L(egio) VII G(emina) en cartela rectangular.

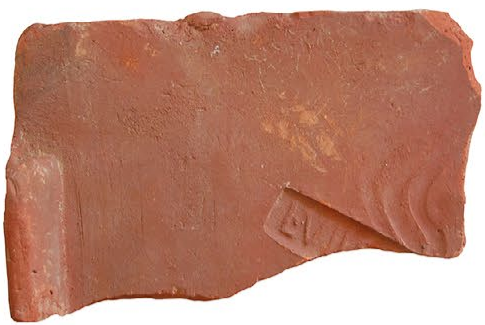

35

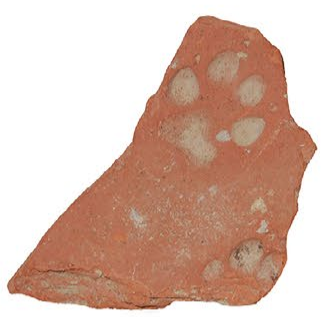

38

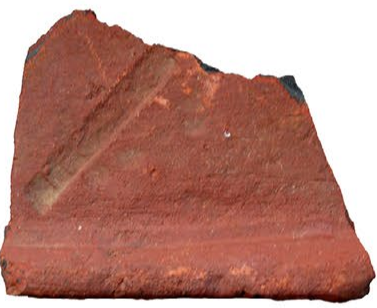

42

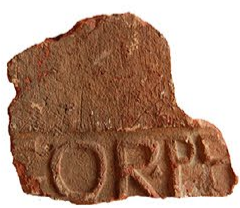

45



50

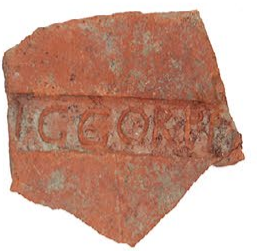

39
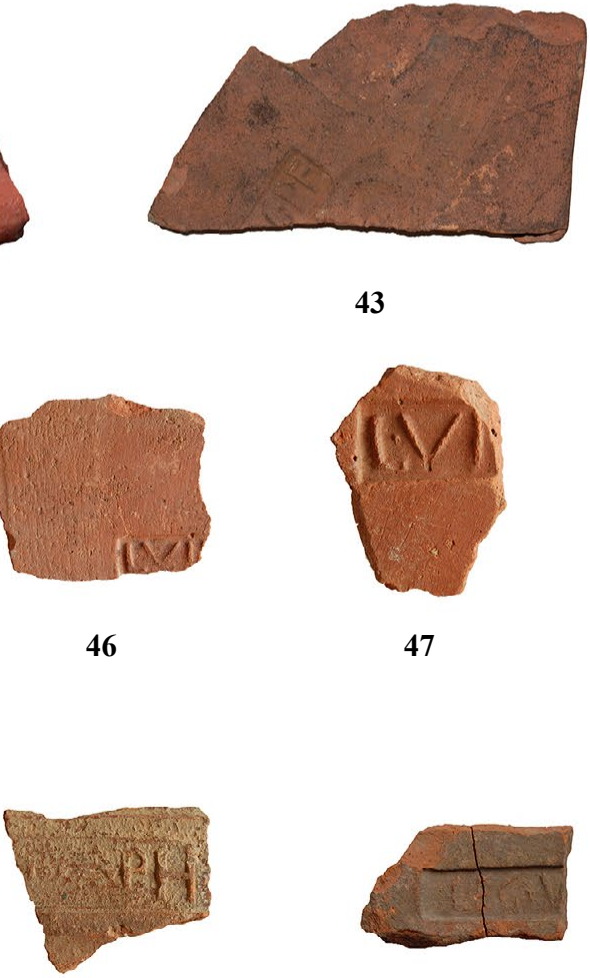

51
43

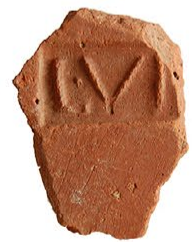

47

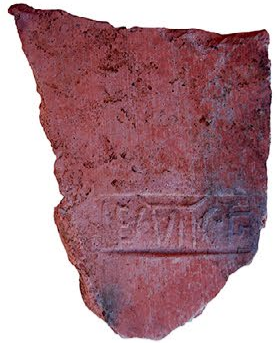

36

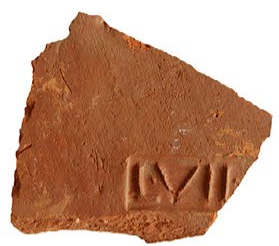

40

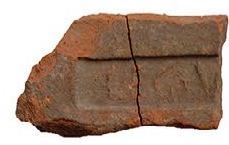

52

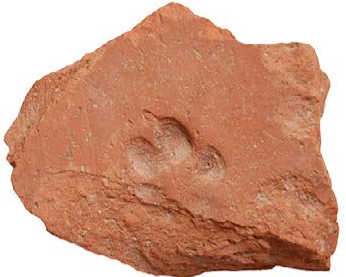

37

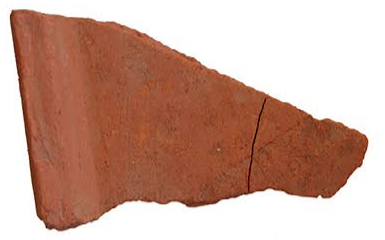

41

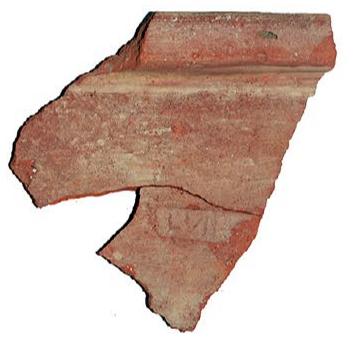

44



48

49

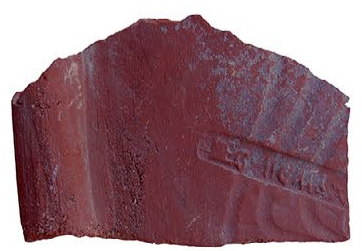

54

Figura 9: Tegulae (nº 35-52; 54). 


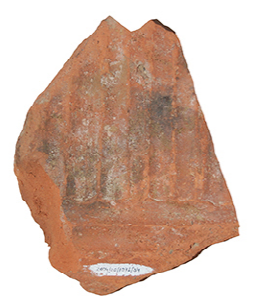

55

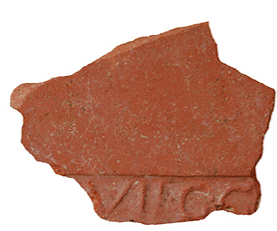

59

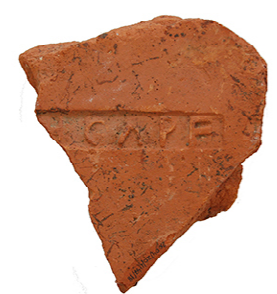

63

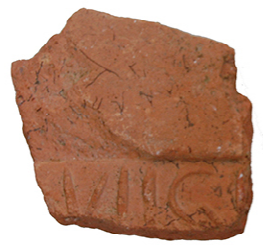

67

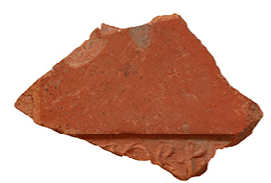

56

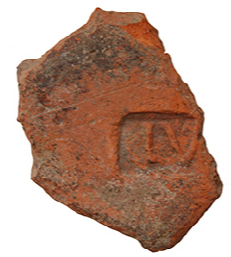

60

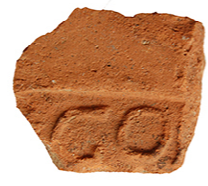

64

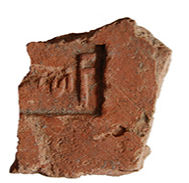

69

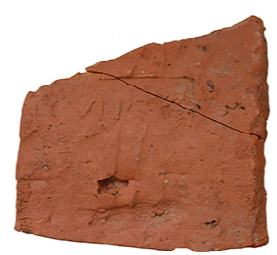

57

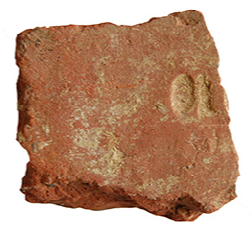

61

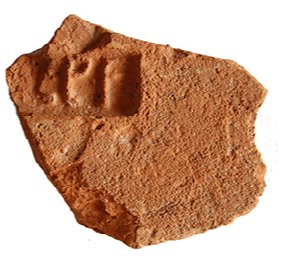

65

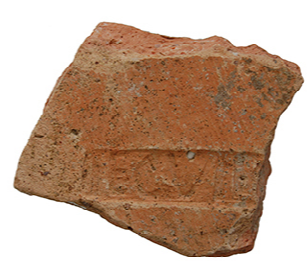

70

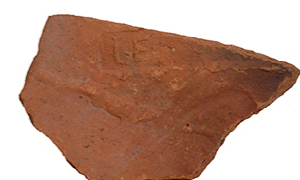

58



62

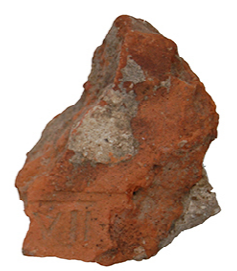

66

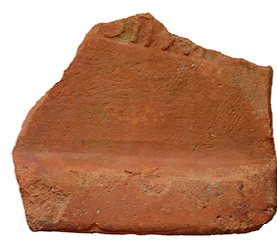

71



Figura 10: Tegulae (n ${ }^{\mathrm{o}} 55-67 ; \mathrm{n}^{\circ}$ 69-71).

56. $\quad N^{o}$ inv. 2004/20/1071/35; Área 1000 (Puerta); UE 1071 (Figs. 10 y 19)

Fragmento de tegula

Dimensiones: $12 \times 7 \times 3 \mathrm{~cm}$

Dimensiones de la cartela: $2,8 \times$ [9] $\mathrm{cm}$

Sello: [Legio VII] Gor(diana) P(ia) F(elix) en cartela rectangular.

57. N N $^{\circ}$ inv. 2004/20/1071/36; Área 1000 (Puerta); UE 1071 (Fig. 10)

Fragmento de tegula. Presenta marca de producción consistente en dos líneas rectas y paralelas practicadas con dos dedos.

Dimensiones: 12 × $10 \times 2 \mathrm{~cm}$

Dimensiones de la cartela: $2,8 \times$ [9] $\mathrm{cm}$

Sello: L(egio) VII G(emina) P(ia) en cartela rectangular.
58. $\quad N^{\circ}$ inv. 2004/20/1081/22; Área 1000 (Puerta); UE 1081 (Fig. 10)

Fragmento de tegula

Dimensiones: $15 \times 10 \times 2 \mathrm{~cm}$

Dimensiones de la cartela: $2,8 \times[8,5] \mathrm{cm}$

Sello: Le(gio) [VII Gemina ...]

59. No inv. 2004/20/1082/29; Área 1000 (Puerta);

UE 1082 (Figs. 10 y 19)

Fragmento de tegula

Dimensiones: $12,5 \times 9,5 \times 3 \mathrm{~cm}$

Dimensiones de la cartela: $3 \times$ [9] $\mathrm{cm}$

Sello: [Legio] VII G(emina) G(ordiana) [...] en cartela rectangular.

60. No inv. 2004/20/1116/24; Área 1000 (Puerta);

UE 1116 (Fig. 10)

Fragmento de tegula 




72

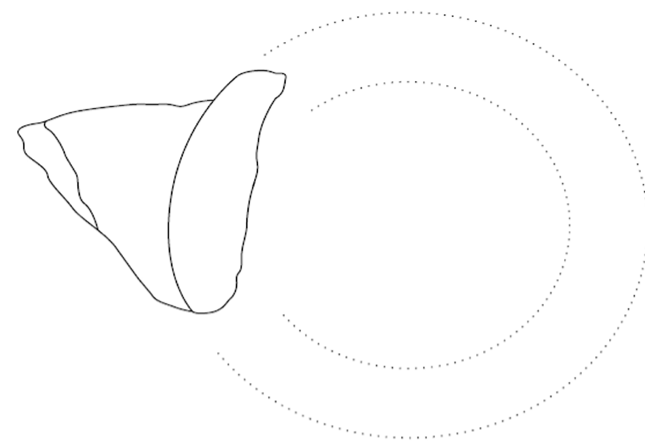

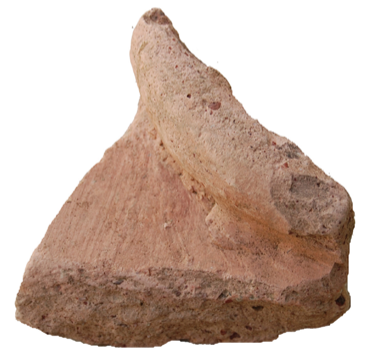

73

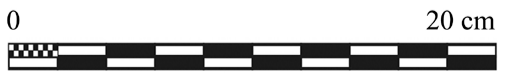

Figura 11: Tegulae con orificio central $\left(\mathrm{n}^{\mathrm{o}} 72\right)$ y oculus $\left(\mathrm{n}^{\mathrm{o}} 73\right)$.

Dimensiones: $10 \times 7 \times 2,5 \mathrm{~cm}$

Dimensiones de la cartela: $2 \times[3] \mathrm{cm}$

Sello: L(egio) V[II Gemina...] en cartela rectangular.

61. $\mathrm{N}^{\mathrm{o}}$ inv. 2004/20/1126/26; Área 1000 (Puerta);

UE 1126 (Fig. 10)

Fragmento de tegula

Dimensiones: $6,5 \times 6 \times 3,1 \mathrm{~cm}$

Dimensiones de la cartela: 2 x $[1,5] \mathrm{cm}$

Sello: L(egio) [VII Gemina...] en cartela en forma de tabula ansata

62. $N^{\circ}$ inv. 2004/20/1126/27; Área 1000 (Puerta); UE 1126 (Fig. 10)

Fragmento de tegula con superficie estriada. Presenta una marca de producción circular realizada con dos dedos realizada en torno al sello legionario.

Dimensiones: 19, 5 x 16, 5 × $3 \mathrm{~cm}$

Dimensiones de la cartela: 2,1 x [9,5] cm

Sello: Le[g](io) [VII Gemina...] en cartela rectangular

63. $\mathrm{N}^{\mathrm{o}}$ inv. 2004/20/1147/18; Área 1000 (Puerta); UE 1147 (Figs. 10 y 17)

Fragmento de tegula

Dimensiones: $15,3 \times 12 \times 3,5 \mathrm{~cm}$

Sello: [Legio V]II G(emina) A(ntoniniana) $\mathrm{P}($ ia) $\mathrm{F}$ (elix)
64. $\mathrm{N}^{\mathrm{o}}$ inv. 2004/20/1506/12; Área 1000 (Puerta); UE 1506 (Figs. 10 y 19)

Fragmento de tegula

Dimensiones: 6 × 5 × $3 \mathrm{~cm}$

Dimensiones de la cartela: $2,8 \times$ [5] $\mathrm{cm}$

Sello: [Legio VII G(emina)] Gor(diana) [...] en cartela rectangular.

65. $\mathrm{N}^{\mathrm{o}}$ inv. 2004/20/1515/13; Área 1000 (Puerta); UE 1515 (Fig. 10)

Fragmento de tegula, estriada por su parte interna

Dimensiones: 10, 6 × $10 \times 3 \mathrm{~cm}$

Dimensiones de la cartela: 2, 7 x [5] $\mathrm{cm}$

Sello: [Legio VII Gemina Go]r(diana) P(ia) $\mathrm{F}$ (elix) en cartela rectangular.

66. $\quad N^{\circ}$ inv. 2004/20/4010/22; Área 4000 (Termas); UE 4010 (Fig. 10)

Fragmento de tegula

Dimensiones: 11,5 x $10 \times 4,5 \mathrm{~cm}$

Dimensiones de la cartela: $2,8 \times[11,5] \mathrm{cm}$ Sello: [Legio] VII [...] en cartela rectangular.

67. $\mathrm{N}^{\mathrm{o}}$ inv. 2004/20/4010/23; Área 4000 (Termas); UE 4010 (Figs. 10 y 13)

Fragmento de tegula

Dimensiones: $10 \times 9,5 \times 2 \mathrm{~cm}$

Dimensiones de la cartela: $2,8 \times[10] \mathrm{cm}$ 


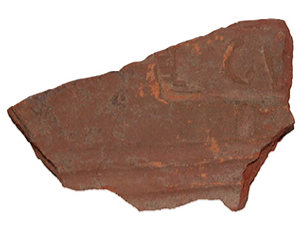

74

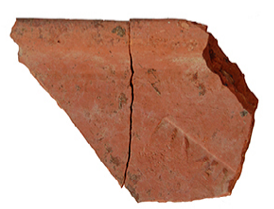

79

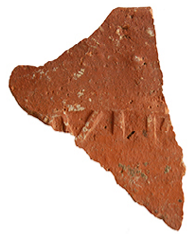

75

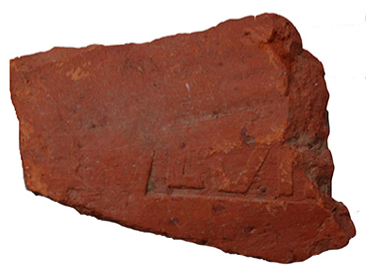

80

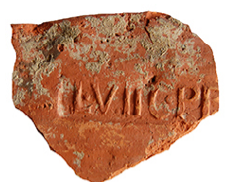

76

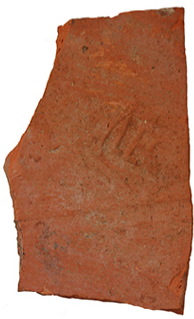

81

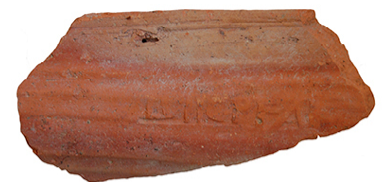

77



82

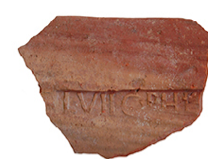

78

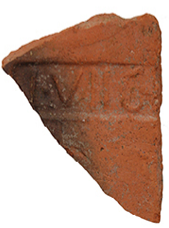

83

Figura 12: Imbrices (n $\left.{ }^{\circ} 74-83\right)$.

Sello: [Legio] VII G(emina) [...] en cartela rectangular.

68. $\mathrm{N}^{\mathrm{o}}$ inv. 2004/20/4038/48; Área 4000 (Termas); UE 4038 (Fig. 10)

Fragmento de tegula

Dimensiones: $8 \times 7,5 \times 2 \mathrm{~cm}$

69. No inv. 2004/20/4067/07; Área 4000 (Termas); UE 4067 (Fig. 10)

Fragmento de tegula

Dimensiones: 7 × 5 × $2 \mathrm{~cm}$

Dimensiones de la cartela: $3 \times$ [ [4] $\mathrm{cm}$

Sello: [...] F(elix). La letra $F$ es de mayor altura que los caracteres anteriores, que no se pueden reconocer. Cartela rectangular.

70. $\quad N^{\circ}$ inv. 2004/20/5014/13; Área 5000 (Termas); UE 5014 (Figs. 10 y 13)

Fragmento de tegula

Dimensiones: $16,5 \times 12,5 \times 3 \mathrm{~cm}$

Dimensiones de la cartela: $3,8 \times[9,5] \mathrm{cm}$

Sello inciso: Leg(io) VII G(emina) [...] en cartela rectangular

71. $\mathrm{N}^{\mathrm{o}}$ inv. 2004/20/5019/07; Área 5000 (Termas); UE 5019 (Fig. 10)

Fragmento de tegula con pestaña

Dimensiones: 18, 4 × 15, 7 × $3 \mathrm{~cm}$

Dimensiones de la cartela: 2, 5 x 9,5 cm

Sello: L(egio) VII G(emina) [...]

72. $\mathrm{N}^{\mathrm{o}}$ inv. 2004/20/1508/15; Área 1000 (Puerta); UE 1508 (Fig. 11)

Fragmento de tegula con orificio circular de 1 $\mathrm{cm}$ de diámetro.

Dimensiones: $12 \times 9 \times 3 \mathrm{~cm}$

73. $N^{\circ}$ inv. 2004/20/4014/14; Área 4000 (Termas); UE 4014 (Fig. 11)
Fragmento de tegula con oculus central de 18 $\mathrm{cm}$ de diámetro, circundado por un reborde.

Dimensiones: 12 x 11, 5 x 7, $5 \mathrm{~cm}$

Imbrices

74. $\quad \mathrm{N}^{\circ}$ inv. 2004/20/04 (Fig. 12)

Pequeño fragmento de imbrex con superficie estriada

Dimensiones: $14 \times 9 \times 3 \mathrm{~cm}$

Dimensiones de la cartela: 4 x [6,6] cm

Sello: L(e)g(io) V[II ---] en cartela rectangular

75. $\mathrm{N}^{\circ}$ inv. 2004/20/1014/38; Área 1000 (Puerta);

UE 1014 (Fig. 12)

Fragmento de imbrex

Dimensiones: $11,3 \times 8 \times 2,6 \mathrm{~cm}$

Dimensiones de la cartela: $1,5 \times 6,5 \mathrm{~cm}$

Sello: L(egio) VII G(emina) [....] en cartela rectangular

76. $\quad \mathrm{N}^{\mathrm{o}}$ inv. 2004/20/1515/12; Área 1000 (Puerta);

UE 1515 (Figs. 12 y 16)

Fragmento de imbrex

Dimensiones: 11,6 × $10 \times 2,5 \mathrm{~cm}$

Dimensiones de la cartela: $2,6 \times[8,5] \mathrm{cm}$

Sello: L(egio) VII G(emina) P(ia) F(elix) en cartela rectangular.

77. $\mathrm{N}^{\circ}$ inv. 2004/20/1071/33B; Área 1000 (Puerta);

UE 1071 (Fig. 12)

Gran fragmento de imbrex

Dimensiones: 25 x $12,5 \times 3 \mathrm{~cm}$

Dimensiones de la cartela: $2,6 \times 9 \mathrm{~cm}$

Sello: L(egio) VII G(emina) P(ia) F(elix)

A(ntoniniana) en cartela rectangular.

78. $\quad N^{\circ}$ inv. 2004/20/1071/33C; Área 1000 (Puerta); UE 1071 (Fig. 12) 
Fragmento de imbrex

Dimensiones: $16 \times 13 \times 2 \mathrm{~cm}$

Dimensiones de la cartela: 2,8 x $9 \mathrm{~cm}$

Sello: L(egio) VII G(emina) Ph(i)l(ippiana)

$[\ldots]$ en cartela rectangular.

79. $\quad \mathrm{N}^{\mathrm{o}}$ inv. 2004/20/1071/37; Área 1 (Puerta); UE 1071 (Fig. 12)

Fragmento de imbrex

Dimensiones: $10 \times 9 \times 2,5 \mathrm{~cm}$

Dimensiones de la cartela: 2 x [6] $\mathrm{cm}$

Sello: L(egio) VII [...]

80. $\quad \mathrm{N}^{\circ}$ inv. 2004/20/1071/33D; Área 1 (Puerta); UE 1071 (Fig. 12)

Fragmento de imbrex

Dimensiones: $20 \times 13 \times 3 \mathrm{~cm}$

Dimensiones de la cartela: $3 \times$ [7] $\mathrm{cm}$

Sello: L(egio) VII [Gemina...]

81. No inv. 2004/20/1071/33E; Área 1 (Puerta); UE 1071 (Fig. 12)

Gran fragmento de imbrex. Presenta marca de producción consistente en dos líneas rectas y paralelas practicadas con dos dedos.

Dimensiones: $20 \times 11,5 \times 3 \mathrm{~cm}$

Dimensiones de la cartela: 2, $6 \times$ [5] $\mathrm{cm}$

Sello: Leg(io) [VII Gemina...]

82. No inv. 2004/20/1071/33F; Área 1 (Puerta); UE 1071 (Fig. 12)

Gran fragmento de imbrex

Dimensiones: 17 × 15 × $3 \mathrm{~cm}$

Dimensiones de la cartela: 3 x [9] $\mathrm{cm}$

Sello: L(egio) V[II Gemina...]

83. 2004/20/1508/15; Área 1 (Puerta); UE 1508 (Fig. 12)

Fragmento de imbrex

Dimensiones: $10,5 \times 7,5 \times 3 \mathrm{~cm}$

Dimensiones de la cartela: $2 \times[6,5] \mathrm{cm}$

Sello: L(egio) VII G(emina) [...]

Pavimentos

84-85. $\quad \mathrm{N}^{\mathrm{o}}$ inv. 2004/20/1014/39, 2004/20/1014/40, 2004/20/1014/42; Área 1000 (Puerta); UE 1014

86-90. $\quad \mathrm{N}^{\mathrm{o}}$ inv. 2004/20/4010/24 hasta 2004/ 20/4010/29; Área 4000 (Termas); UE 4010

91-101. $\quad \mathrm{N}^{\mathrm{o}}$ inv. 2004/20/4021/10 hasta 2004/ 20/4021/20; Área 4000 (Termas); UE 4021

102-105. $\mathrm{N}^{\mathrm{o}}$ inv. 2004/20/4038/50 hasta 2004/ 20/4038/53; Área 4000 (Termas); UE 4038

106-116. $\mathrm{N}^{\mathrm{o}}$ inv. 2004/20/4048/14 hasta 2004/ 20/4048/24; Área 4000 (Termas); UE 4048

117-205. $\mathrm{N}^{\mathrm{o}}$ inv. 2004/20/5000/01 hasta 2004/ 20/5000/89; Área 5000 (Termas); UE 5000

206-210. No inv. 2004/20/5012/07 hasta 2004/

20/5012/11; Área 5000 (Termas); UE 5012

211-312. $\mathrm{N}^{\mathrm{o}}$ inv. 2004/20/5015/01 hasta 2004/ 20/5015/101; Área 5000 (Termas); UE 5015

313-323. $\mathrm{N}^{\mathrm{o}}$ inv. 2004/20/5019/08 hasta 2004/ 20/5019/18; Área 5000 (Termas); UE 5019
Números de inventario correspondientes a pequeños ladrillos empleados en la construcción de pavimentos de opus spicatum. Sus módulos oscilan entre 8-10, 5 $\mathrm{cm}$ de longitud, 3, 5- 4, $5 \mathrm{~cm}$ de anchura y 2, 2-3 cm de altura.

\section{ANÁLISIS DEL MATERIAL LATERICIO}

Las intervenciones arqueológicas desarrolladas en el sector de Puerta Obispo de la ciudad de León han permitido identificar una considerable variedad de material constructivo fabricado en arcilla cocida. Entre ellos se encuentran elementos de sustentación, cubiertas, pavimentos y concamerationes propias de estancias calefactadas.

Entre los elementos sustentantes, se han constatado ladrillos de diversa forma, entre los que destacan bessales y pedales, además de varias piezas fragmentarias de dimensiones indeterminadas. El ladrillo bessalis o besal tiene una forma cuadrada, de unos dos tercios de pie $(19,7 \mathrm{~cm})$ de lado. Vitrubio (De Arch. $\mathrm{V}, 10,2)$ vincula este tipo a la construcción de las $p i$ lae cuadradas del sistema de hipocausis (laterculus bessalis); las evidencias arqueológicas confirman la asociación de este tipo a establecimientos balnearios (Fernández Ochoa et alii, 1999, 296). En las termas hispanas se confirma que las dimensiones de los lateres bessales pueden ser algo variables, oscilando entre 18 y $24 \mathrm{~cm}$ de lado, intervalo que coincide con el promedio señalado por Brodribb para Britannia $(1987,34)$. Los tres ejemplares que aquí presentamos de las excavaciones leonesas en Puerta Obispo (Fig, $\left.3, n^{\circ} 1-3\right)$ se encuentran completos y sus dimensiones coinciden con el patrón ya tipificado $(18,7,19$ y 23 $\mathrm{cm})$. Todos ellos fueron recuperados durante las obras de adecuación de los restos para su musealización, al desmantelar el canal de desagüe que rodeaba las letrinas de las termas por el este, donde habían sido reutilizados en un momento indeterminado de los siglos II-III d. C.

Junto a la variante de ladrillo besal se han identificado tres elementos más correspondientes a pedales (Fig. 4). El pedalis o tetradoron corresponde al módulo básico de medidas romanas, el pes o pie romano (unos 29, $6 \mathrm{~cm}$ ) de lado. Según la normativa vitrubiana, este tipo se empleaba a modo de basa y capitel de las pilae del hipocausto (De Arch. II, 3, 3). Sin embargo, en las termas hispanas se constata su uso para otros fines dentro de los edificios termales, como construcción de muretes y bocas de horno (Fernández Ochoa et alii, 1999, 296). En el caso de las piezas que aquí presentamos, los lateres pedales proceden del desmantelamiento del mencionado canal oriental perimetral de las letrinas, donde fueron reutilizados en su momento, por lo que no podemos pronunciarnos sobre su procedencia original. Por lo que se refiere a sus dimensiones, dos de ellos ( $\mathrm{n}^{\mathrm{o}} 5$ y 6 ) presentan medidas canónicas (30 y 29 respectivamente), mientras 
que el tercero $\left(\mathrm{n}^{\circ} 4\right)$ resulta algo más reducido $(25,5$ $\mathrm{cm})$. De hecho, resulta demasiado grande para integrarlo dentro del grupo de ladrillos bessales, por lo que lo consideramos una variedad más reducida de pedal.

Dentro del conjunto de ladrillos se constatan también varios que parecen haber formado parte de pilae $\mathrm{o}$ columnillas circulares de hipocausto (Brodribb, 1987, 54-55) (Fig. 6). Entre ellos destaca una pieza semicircular de $19 \mathrm{~cm}$ de diámetro $\left(\mathrm{n}^{\circ} 11\right)$, cinco ladrillos en cuarto de círculo ( $\left.\mathrm{n}^{\circ} 12-16\right)$, de entre 31 y $40 \mathrm{~cm}$ de diámetro, y uno $\left(\mathrm{n}^{\circ} 17\right)$ en octavo de círculo, de $30 \mathrm{~cm}$ de diámetro. Los lateres circulares completos suelen presentar medidas de entre 12 y $23 \mathrm{~cm}$ (Degbomont, 1984, 101). Los ladrillos de tendencia circular (semicirculares, en cuarto de círculo o en octavo de círculo), que configuran en módulo más reducido las columnas en mampostería de atrios, pórticos y peristilos, tienen diámetros bastante mayores, tal y como se verifica en nuestros ejemplares. En el caso de las termas de Carteia se han documentado pilae realizadas con ladrillos semicirculares de $32 \mathrm{~cm}$ de diámetro (Roldán Gómez, 1992, 127; Fernández Ochoa et alii, 1999, 296). Uno de los ejemplares de cuarto de círculo recuperados en León presenta un radio de $20 \mathrm{~cm}\left(\mathrm{n}^{\circ} 15\right)$, lo que supone un diámetro de al menos el doble $(40 \mathrm{~cm})$. El resto se concentra en torno a los $31-32 \mathrm{~cm}$ de diámetro. La pieza semicircular $\left(\mathrm{n}^{\circ} 11\right)$ representa una pila más estilizada, de $19 \mathrm{~cm}$ de diámetro.

La presencia de ladrillos de tendencia circular formando pilae de hipocausto ha sido escasamente constatada en establecimientos termales (Fernández Ochoa y Zarzalejos, 1996, 116). En Hispania se documentan en Ilici, Lancia, Asturica y Santander, además de Carteia (Fernández Ochoa et alii, 1999, 296). Los ladrillos semicirculares y en cuadrante de círculo ya habían sido constatados en las termas legionarias de León durante las obras de restauración, aunque al igual que los nuestros, habían aparecido descontextualizados (García y Bellido, 1970, 577). En la Galia Narbonense se ha datado su aparición en un momento avanzado, correspondiente a la segunda mitad del siglo II d. C. (Bouet, 1999, 164). Los ejemplares hallados en Puerta Obispo proceden claramente del desmantelamiento de estructuras romanas para adecuar museográficamente los restos, o de unidades estratigráficas (UE 4014 y 1071) correspondientes a reformas bajoimperiales de estructuras previas, por lo que no se puede precisar de ninguna forma su cronología de uso originario.

Dentro de los estudios relativos a material latericio de época romana, las estancias calefactadas de las instalaciones balnearias constituyen uno de los capítulos que ha atraído preferentemente la atención de los investigadores, existiendo una abundante bibliografía al respecto ( $v$. Helen, 1975; Degbomont, 1984; Brodribb, 1987; Bouet, 1999; Fernández Ochoa y Zarzalejos, 1996; Fernández Ochoa et alii, 1999). Junto a los elementos de sustentación (pilas y arquillos) de las suspensurae, los materiales de las concamerationes o dobles paredes (tegulae mammatae, tubuli, bobinas) constituyen uno de los testimonios más evidentes sobre la existencia de caldaria o sudationes en termas o baños romanos, aunque en la mayoría de los casos aparecen en estado fragmentario y fuera de su posición original, debido al arrasamiento de las paredes de las habitaciones calefactadas. A la nómina de instalaciones balnearias que contaron con este tipo de elementos (Fernández Ochoa et alii, 1999, 299), debemos sumar los recientes hallazgos en Turiaso (Beltrán Llorís y Paz Peralta, 2004, 69, Fig. 28.1).

Ya en su momento García y Bellido (1970) planteó la existencia de estancias con dobles paredes en las termas romanas halladas bajo la catedral de León. Los materiales que aquí presentamos confirman dicha afirmación, proporcionando elementos de sistemas tan diferentes como tegulae mammatae y tubuli. En efecto, se han documentado en la intervención de Puerta Obispo tres fragmentos con los característicos apéndices de tegulae mammatae (Vitrubio, De Arch. VII, 4, 2; Plinio, Nat. Hist. XXXV, 46, 159), grandes tejas cuadradas o cuadrangulares, con cuatro apéndices o mamelones dispuestos regularmente en una de sus caras a fin de crear una cavidad entre dos paredes verticales como espacio de aireación. Dos de ellos son apéndices troncopiramidales (Fig. 7, no 18 y 19), mientras el tercero (Fig. 7, $\mathrm{n}^{\circ}$ 20) presenta una protuberancia circular. Ambas variantes fueron ya establecidas por Brodribb (1987, 60-62), quien las clasifica como tipos A y B respectivamente, proponiendo que las diferencias en cuanto a la forma y anchura de sus mamelones derivaba de un uso diferenciado, que sin embargo no queda bien especificado. Recientemente Bouet ha establecido una nueva clasificación que en esta ocasión se basa en la longitud de los mamelones (Grupos 1 y 2) (Bouet, 1999, 13-39).

Junto a las tegulae mammatae se documentan catorce fragmentos pertenecientes a un número indeterminado de tubuli latericii (Fig. 8, $\mathrm{n}^{\mathrm{o}}$ 21-34), ladrillos rectangulares huecos que se empalmaban verticalmente para constituir concamerationes. Se fijaban a la pared mediante una capa de mortero y la cara exterior quedaba oculta por un revoco, motivo por el cual suelen presentar los lados mayores estriados para facilitar la adherencia, como en el caso de las piezas que aquí presentamos.

Ninguna observación cronológica podemos extraer de la posición estratigráfica de los elementos de las concamerationes recuperados, ya que aparecen todos ellos en horizontes de amortización posteriores (UE $1105,4014,4021$ y 5019), donde han sido empleados como elementos de relleno y compactación de tierra, claramente desplazados de sus posiciones originarias en las cámaras calefactadas de las vecinas termas legionarias.

Uno de los conjuntos mejor representados es el de los elementos para cubiertas. Tégulas e ímbrices constituyen elementos muy frecuentes, no solo en las intervenciones desarrolladas en Puerta Obispo, sino en 
cualquier excavación de época romana. Sin embargo, este material latericio apenas se ha estudiado desde un punto de vista técnico y arqueoarquitectónico. Para la antigua Hispania carecemos de análisis pormenorizados semejantes a los que se han llevado a cabo en otras antiguas provincias romanas como Britania (Warry, 2006; 2006b). Este investigador aborda un análisis tipológico comparativo de los materiales latericios destinados a techumbres, que aporta interesantes reflexiones arquitectónicas y productivas sobre este tipo de manufactura. Estos elementos pueden formar parte asimismo de infraestructuras hidráulicas e incluso su emplearon como base de las suspensurae (Fernández Ochoa y Zarzalejos, 1996, 116).

Presentamos aquí 39 fragmentos de tegulae $\left(\mathrm{n}^{\circ} 35\right.$ 73) (Fig. 9-11) y 10 de imbrices (n $n^{\circ}$ 74-83) (Fig. 12) recuperadas durante las intervenciones arqueológicas desarrolladas en el sector de Puerta Obispo (León). Las tejas se suelen clasificar a partir de sus dimensiones y la forma que adoptan sus pestañas (en el caso de las tégulas planas), aunque pocas veces se conservan completas, como consecuencia del desplome de las techumbres y el desmantelamiento de los edificios. En nuestro caso todas han llegado en estado fragmentario. Todas se encuentran en posición secundaria dentro de las estratigrafías, empleadas junto con tierras como capas de preparación para pavimentos (UE 4021 y 1071) y calles (UE 1508, 1515 y 1116) o simples niveles de relleno o aterrazamiento (UE 1014, 1021, 1032, 1081, 1082, 1147, 4010, 4067, 5014), datados en su mayoría en el periodo bajoimperial o tardoantiguo, e incluso medieval (UE 1043, 1126, 1506 y 5019).

En el caso de los materiales latericios para techumbre, a diferencia de los ladrillos y elementos de concamerationes, recuperados principalmente en el sector de la excavación correspondiente a las letrinas de las antiguas termas legionarias, se verifica que proceden en su mayoría del sector correspondiente a la puerta romana del campamento (UE 1014, 1020, 1021, 1032, 1043 , 1071, 1081, 1082, 1116, 1126, 1147, 1506, $1508,1515)$. Un magnífico ejemplo en este sentido lo constituye la UE 1071, datada en el tránsito entre los siglos III y IV d. C., que corresponde con la erección de la muralla bajoimperial y las reformas estructurales que tuvieron lugar en la porta principalis sinistra de época flavio-trajanea, que debieron suponer la amortización de parte del material de las cubiertas (Morillo y García Marcos, 2005; Fernández Ochoa et alii, 2011, 271). En dicha unidad se ha recuperado casi la tercera parte de los fragmentos de tégulas e ímbrices, formando parte de un nivel de relleno que recreció el nivel de circulación del pavimento del antiguo cuerpo de guardia de la torre, formado por tierras acompañadas de diversos materiales cerámicos y numismáticos muy bien datados en época tetrárquica.

Debemos señalar asimismo la presencia de un fragmento de tegula plana con un oculus circular de $18 \mathrm{~cm}$ de diámetro, circundado por un alto reborde (Fig. 11, no 73). Estos elementos, interpretados como tejas-tragaluz destinadas a la iluminación o ventilación de las estancias inferiores (cocinas, estancias calefactadas), cuyo borde evitaría la entrada de agua por los orificios, resultan muy poco habituales (Adam, 1996, 231, Fig. 500). Brodribb recoge tan sólo tres de estos elementos en Britania y Galia (1987, 19-20, Fig. 10.1). También se constata su presencia puntual en Pompeya y Herculano. Por lo que se refiere a Hispania, recientemente se han dado a conocer dos en el fuerte de la cohors I Celtiberorum en Cidadela (A Coruña) (Carlsson-Brandt, 2011, 168) y otros tres ejemplares hallados en el alfar de La Venta del Carmen (Los Barrios, Cádiz) (Redondo y Borge, 1998, 341). Conocemos la existencia de un ejemplar más aparecido en la ciudad romana de Bracara Augusta, procedente de las Termas do Alto da Cividade y expuesto actualmente en el Museo D. Diogo de Sousa. En Puerta Obispo se documenta en una capa de relleno asociada a la calle de época bajoimperial (UE 4014).

Uno de los ejemplares de tégula recuperados (Fig. $11, \mathrm{n}^{\mathrm{o}}$ 72) presenta un orificio de $1 \mathrm{~cm}$ de diámetro destinado a un clavo de sujeción de la cubierta a la estructura de madera del tejado, que resultan mucho más habituales de lo que parece (Warry, 2006, 102-104).

El último conjunto de material latericio corresponde a ladrillos para pavimento. Se han documentado 240 ladrillos rectangulares de pequeño tamaño, de entre 8 y 10, $5 \mathrm{~cm}$ de longitud, 3, 5-4, 5 de anchura y 2, 2-3 cm de altura, que formaron parte de suelos de opus spicatum, donde se colocaban yuxtapuestos por su cara más estrecha formando el característico diseño en espiga o espina de pez. Los pavimentos de este tipo son muy habituales en estancias termales (Bouet, 1999, 169-178; Roldán Gómez, 1999, 199) o instalaciones artesanales de diverso tipo (fullonica, torcularia), debido a las propiedades hidrófugas del ladrillo. En el caso de los ejemplares recuperados en León, se documentaron en diversas unidades estratigráficas asociadas al desmantelamiento de suelos de las termas legionarias, donde se conserva todavía un pavimento in situ de opus spicatum asociado a una primera fase constructiva, en la que se identifica una estancia con muros revestidos de opus signinum (piscina de frigidarium) ${ }^{3}$, posteriormente reformada $\mathrm{y}$ convertida en unas letrinas y sus correspondientes canales de desagüe (García Marcos et alii, 2004). No cabe duda de que los ladrillos recuperados proceden en su mayoría de este pavimento, amortizado parcialmente a finales del siglo I o comienzos del II d. C. De hecho, uno de los conjuntos más numerosos se recuperó durante las labores de limpieza de las letrinas (UE 5000). El resto procede de horizontes de relleno bajoimperiales y tardoantiguos (UE 1014, 4010, 4021, $4038,5012,5015$ y 5019). Dos de estas unidades (UE

\footnotetext{
3. El empleo de opus spicatum como pavimento para natatio se ha constatado, por ejemplo, en las termas de la ciudad romana de Cemenelum (Cimiez, Niza) (Benoit, 1977, 85).
} 
5015 y 5019) corresponden a la amortización de los canales perimetrales de desagüe de las letrinas, situados al este y al sur, cuyos pavimentos eran, como ya apuntamos, de opus spicatum. El marco temporal que presentan los materiales cerámicos y numismáticos que acompañan a estos ladrillos confirma que, al menos a mediados del siglo III d. C. las letrinas dejaron de utilizarse (Morillo y Gómez Barreiro, 2006, 289), momento a partir del cual sus estructuras comenzaron posiblemente a ser desmanteladas.

\section{SELLOS, MARCAS E IMPRONTAS}

Uno de los aspectos del material latericio romano que ha recibido mayor atención por parte de la investigación es precisamente el de las marcas y sellos impresos, normalmente a partir de matrices de madera, metal o arcilla. Dicho criterio se ha empleado para establecer talleres, áreas productivas y posibles circuitos de comercialización, además de movimientos de unidades de tropa en el caso de las marcas militares. Las características de dichos sellos han quedado bastante bien definidas, especialmente para Roma y el valle del Tíber, gracias a trabajos como los de Bloch (1938; 1967), Helen (1975), Steinby (1974-75; 1999), Setälä (1977), Manacorda (2000) y Bruun (2005; 2005b). En la Península Ibérica los primeros estudios y mapas de dispersión de marcas sobre tejas y ladrillos romanos (Rico, 1995; 1999; 2000) han dado paso a un repertorio creciente de producciones (v. entre otros Duran Cabello, 1998; Abascal et alii, 2000; Fernández Vega et alii, 2009; Abascal, 2010; Cebrián, 2010). Sin embargo, por el momento carecemos de un corpus regional o provincial semejante al que se ha publicado en Bélgica (De Poorter y Claeys, 1989).

Las producciones latericias con marcas militares, dentro de las que se enmarcan los ejemplares de León que aquí presentamos, han recibido especial atención en las provincias septentrionales del Imperio, allí donde se encontraba destacado el grueso de las tropas romanas a partir de Augusto. Análisis como los de Mc Whirr (Ed.) (1979), Brodribb (1987) y Le Bohec (1992) han ido perfilando los tipos, nomenclatura y funciones del material sellado por el ejército. La reciente monografía de Kurzmann (2006) constituye un magnífico estado de la cuestión al respecto, en el que quedan perfectamente definidos nuestros conocimientos y carencias.

A diferencia de las regiones como Britania, en las que se concentran las tropas romanas, donde la primera producción latericia fue sin duda militar (Darvill y Mc Whirr, 1984, 247), la situación en la antigua Hispania presenta rasgos diferentes. El material latericio sellado es mucho menos numeroso, debido principalmente a la reducida presencia militar a partir del periodo flavio, momento en que la marca militar se regulariza y se extiende el hábito epigráfico (Le Roux, 1999, 111). La producción más amplia y mejor documentada es la firmada por la legio VII gemina en su campamento estable de León, cuyos rasgos básicos fueron ya definidos por García y Bellido (1970, 588-599). Como ya señalamos más arriba, publicaciones posteriores han ampliado el catálogo de materiales (Liz y Amaré, 1993; González Fernández, 1994; Fernández Freile, 2003; Campomanes, 2006; Amaré y Álvarez Vega, 2006; Morillo y Salido, e.p.).

El ejército romano marca sus tejas y ladrillos como signo de autoridad y propiedad, seguramente para distinguirlo de las producciones civiles (Peacock, 1982, 137). La distribución de la producción militar está en principio localizada y confinada dentro de los límites marcados por la jurisdicción del ejército (Darvill y Mc Whirr, 1984, 247). Esto ha llevado a algunos autores a intentar reconstruir el territorium militaris de las diferentes unidades a partir de la dispersión de sus marcas latericias, cuestión en la actualidad completamente descartada (cf. Kurzmann, 2006, 256-263), al igual que el propio concepto de territorio militar, que está en revisión. A pesar de tratarse de producciones destinadas a la construcción y el mantenimiento de las infraestructuras de los campamentos (termas, alcantarillado, suministro de agua, etc.), su ámbito de dispersión se extiende al hinterland inmediato. En el caso de León alcanza zonas con fuerte presencia de la legio VII gemina como Asturica y sus alrededores, el campamento del ala II Flavia en Rosinos de Vidriales e incluso Italica (cf. Liz y Amaré, 1993, 46). Asimismo se constatan fuera de la Península en Germania, Dacia y la Numidia-África Proconsular, en relación con la presencia de la legio VII gemina o sus destacamentos en estos lugares (Morillo, 2005, 28-29). Queda por determinar si a algunos de estos lugares han llegado traídos por miembros de la propia legión o bien como material reutilizado en momentos posteriores (Mori1lo, 2008, 179).

El hallazgo de una concentración excepcional de material latericio sellado, así como los restos de dos hornos en el valle de Fenar, a una treintena de kilómetros de la actual ciudad de León (Gutiérrez, 1985, 126-127 y 155-160), han permitido situar en esta zona una de las producciones, aunque sin duda existieron talleres mucho más próximos al campamento legionario (Morillo, 2008, 179).

Las excavaciones arqueológicas de Puerta Obispo proporcionan un significativo conjunto de materiales con sello militar que incrementan la nómina de los ya conocidos en la ciudad de León y permiten por primera vez establecer el porcentaje de material sellado ${ }^{4}$.

4. Los porcentajes se han calculado sobre el total del material latericio recuperado. Es evidente que esta cifra es orientativa y puede conllevar errores. En todo caso, la inclusión de fragmentos en los que no se encuentra el sello militar, pero que podrían pertenecer a alguno de los ejemplares con sello incluidos en el catálogo elevaría aún más el porcentaje de material sellado, por lo que creemos que nuestras apreciaciones siguen siendo ilustrativas. De cualquier forma, para 
Hemos recuperado 45 fragmentos con diferentes marcas de la legio VII gemina. La gran mayoría (29) se encuentran sobre tegulae, a las que debemos añadir 10 imbrices y 6 ladrillos del tipo bessal y pedal. Si nos atenemos a los porcentajes, que son lógicamente relativos debido al estado fragmentario en que se han recuperado las piezas, dichas cantidades resultan mucho más ilustrativas. La totalidad de las ímbrices se encuentran selladas, así como un elevado porcentaje de las tégulas (un 80\%). Respecto a los ladrillos, más de la mitad (un 60\%) presenta estampilla. La comparación de dichos porcentajes con los que presentan materiales de otros acantonamientos militares romanos de las fronteras septentrionales ofrece interesantes datos, aunque debamos mantener las cautelas correspondientes ya que los porcentajes de dichos establecimientos se calculan en su mayoría sobre ejemplares completos. En León el porcentaje de sellado es mucho mayor que en cualquiera de ellos, aunque existen significativas diferencias. En acantonamientos de las provincias renanas, como Vetera Castra I, el material estampillado alcanza el 77, 5\%, mientras en Britania se mueve en porcentajes de entre el 0, 5 y el 5\% (v. Kurzmann, 2006, 28), muy alejado de las cifras de León. Estas variaciones pueden obedecer tanto a cuestiones cronológicas, como a la mayor o menor necesidad de distinguir el material militar respecto al ámbito civil, sin olvidarnos de la propia tradición castrense de cada región. Boon señala la dificultad de establecer las correctas proporciones entre material sellado y sin marcas, ya que varían de un edificio a otro y de una fase constructiva a otra (1984, 16-17). Por último, como bien ha apuntado Kurzmann, debemos considerar los porcentajes con cierta precaución, en especial en lo relativo a estudios continentales, que hasta hace pocos años han centrado su atención en las marcas, descartando el resto de material latericio, a diferencia de la escuela británica, que ha acometido estudios latericios de conjunto (Kurzmann, 2006, 27-28).

Uno de los problemas que sigue planteando el material latericio sellado es su correcta adscripción cronológica, ya que carece de fecha consular. La mayoría de los estudios publicados determinan el uso de las marcas a partir de la asignación de los epítetos de las unidades militares. La aplicación de estudios arqueométricos y contextuales permiten avanzar seriamente en este sentido, aunque también poseen

el caso de material latericio, la introducción de criterios correctores como el cálculo del peso en su conjunto (sólo aplicable en casos concretos como techumbres completas derrumbadas en alguna estancia, donde es posible conocer el peso de cada teja y emplearlo como divisor) o el estudio exclusivo de «probables» piezas completas a manera de NMI (número mínimo de individuos), tal y como plantean algunos investigadores (Redondo y Borge, 1998, 231), por otra parte una causística absolutamente inusual en la mayoría de los yacimientos arqueológicos, plantearía una distorsión mucho mayor que los números reales que hemos empleado. claras limitaciones. Sin embargo, hasta el momento apenas se han publicado contextos arqueológicos que permitan precisar el momento concreto de uso de dichas marcas. En el campamento leonés de la legio VII gemina, que subyace bajo el actual casco urbano de León, no sobreviven edificios militares cuyo estado de conservación permita asociar determinadas marcas a una fase constructiva concreta. La única excepción en este sentido es el acueducto, al parecer realizado dentro de un mismo proyecto edilicio (Campomanes, 2006). La datación del material latericio por asociación con otros materiales cerámicos y numismáticos dentro de los mismos contextos estratigráficos podría resultar muy útil, pero suele aparecer en posición secundaria dentro de niveles de relleno datados en época posterior, a veces varios siglos posteriores a su empleo original como material constructivo. Tampoco podemos olvidar su reutilización funcional en momentos posteriores con las posibilidades que ofrece este tipo de material para su uso en la construcción de nuevas edificaciones. Como consecuencia, todo ello dificulta la obtención de datos estratigráficos fiables.

A continuación presentamos las diferentes marcas que hemos documentado en el conjunto. La mayoría de las marcas fueron practicadas en relieve, aunque una es incisa realizada sobre una tegula $\left(\mathrm{n}^{\circ} 70\right)$. No se han constatado marcas retrógradas que, sin embargo, García y Bellido dio a conocer en otros yacimientos de la ciudad de León, como en el Huerto de San Isidoro y Jardín de El Cid (1970, 590-591). Las cartelas son siempre rectangulares, con lados menores rectos o redondeados, algunas en forma de tabula ansata. Por lo que se refiere al tamaño de los sellos, su altura oscila entre 2 y $3 \mathrm{~cm}$, si bien la mayoría presenta en torno a $2,8 \mathrm{~cm}$. Su longitud está entre 9 y $11 \mathrm{~cm}$, aunque depende mucho de la marca empleada y los apelativos presentes a lo largo del tiempo.

\section{LEGIO VII GEMINA}

La marca legio VII gemina, abreviada de diferentes formas («LEG» o «L» para legio $\mathrm{y} « \mathrm{G} »,\langle\mathrm{GE} » \mathrm{o}$ «GEM» para gemina), es la más frecuente. Al menos nueve ejemplares presentan este sello $\left(\mathrm{n}^{\mathrm{o}} 3,5,35,42\right.$, $55,67,70,71,75$ y 83), si bien no podemos descartar que alguno de los fragmentarios también corresponda a esta misma estampilla. El único indicativo cronológico que García y Bellido apunta sobre la aparición de este sello es su posterioridad a octubre del año 69 d. C., fecha de la batalla de Cremona, momento a partir del cual la unidad obtiene el epíteto gemina (1970, 588). Dicha marca se encuentra perfectamente constatada en la epigrafía (cf. Le Roux, 1982; Palao, 2006).

La abundancia de material latericio con este sello en León, a diferencia del que lleva el apelativo felix, obtenido al parecer en el 73-74 d. C., llevó a García y Bellido a plantear que antes de esta fecha se habría desarrollado una gran actividad constructiva en el 
campamento legionario, que atribuye a una vexillatio o destacamento de la legio VII enviado a León antes del desplazamiento del resto de la unidad (1970, 589). Aunque la presencia de un destacamento en León entre el 69 y el $74 \mathrm{~d}$. C. resulta verosímil por diversos motivos (Morillo, 2005, 28), hoy en día debemos descartar la antecedencia de las marcas con apelativo gemina respecto a las que llevan el felix. En primer lugar, se ha constatado la presencia del título felix en material latericio renano anterior al 73-74 d. C. Por otra parte, en los mismos contextos se constata en las marcas de la unidad la convivencia entre los epítetos gemina felix y la aparición del cognomen gemina aislado (Ludowici, 1905, 197-198; 1912, 125-127; Palao, 2010).

El tipo de material en que aparece es variado, pues se selló sobre ladrillos de tipo bessal $\left(\mathrm{n}^{\circ} 3\right)$ y pedal $\left(\mathrm{n}^{\mathrm{o}}\right.$ 5), mayoritariamente sobre tegulae $\left(\mathrm{n}^{\mathrm{o}} 42,55,67,70\right.$, 71 y 75) y también sobre imbrex ( $\left.n^{\circ} 83\right)$, variantes tipológicas ya reseñadas (Liz Guiral y Amaré, 1993, 52; González Fernández, 1994, 115) (Fig. 13).

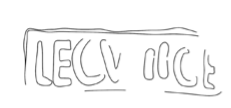

3

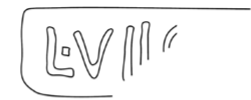

35

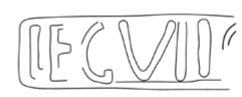

70

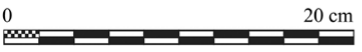

Figura 13: Marcas Legio VII gemina $\left(\mathrm{n}^{\mathrm{o}} 3,35,55,67\right.$ y 70).

\section{LEGIO VII GEMINA FELIX}

Esta marca repite el epíteto nuevo de Felix y aparece abreviado como Leg(io) VII G(emina) F(elix). En las excavaciones de Puerta Obispo se ha localizado solamente un ejemplar de esta estampilla sobre tegula $\left(\mathrm{n}^{\circ}\right.$ 36), con un punzón hasta ahora inédito (Fig. 14).
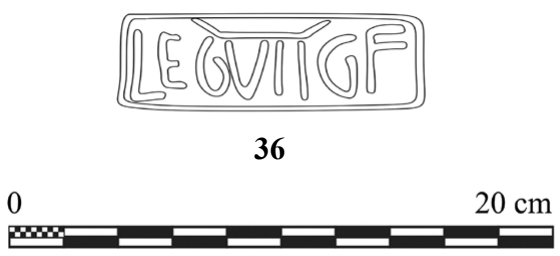

Figura 14: Marcas Legio VII gemina felix $\left(\mathrm{n}^{\mathrm{o}} 36\right)$.

La fórmula se ha constatado en todas las intervenciones arqueológicas publicadas de la capital leonesa (García y Bellido, 1970, 591-92; Liz Guiral y Amaré, 1993, 53; González Fernández, 1994, 116; Fernández
Freile, 2003, 32-42; Amaré y Álvarez Vega, 2006, 726 y 730; Campomanes, 2006, 443-444). Se constata asimismo fuera del campamento legionario, tanto en Hispania (Martín Valls et alii, 2002, n ${ }^{\circ}$ 18-21; García y Bellido, 1970, 592, Fig. 52, 22; 1979, 22, nota 36, Fig. 12; Liz Guiral y Amaré, 1993, 46; Gutiérrez González, 1985, 156-159), como en Numidia (Roldán, 1974, 474, ${ }^{\circ}$ 722) y Dacia (Gudea, 1978, 65-75; Le Roux, 1981, 119-200; Abascal, 1986, 319-322).

\section{LEGIO VII GEMINA PIA}

El epíteto pia asociado a sellos de la Legión VII no se emplea hasta época de Septimio Severo. Su concesión se asocia al apoyo de la legio VII en el conflicto que enfrentó al emperador con Clodio Albino en el año 195. Dicho cognomen aparece por primera vez entre el 208 y 211 (CIL II, 4121), en una inscripción tarraconense de Q. Hedio Lolliano (García y Bellido, 1970, 593). Es curioso que ya en esta inscripción se antepone el nuevo cognomen pia al epíteto felix, anomalía cronológica que se mantendrá en otras variantes de sellos. Hemos recuperado en Puerta Obispo dos estampillas de este tipo ( $n^{\circ} 41$ y 57), ambas sobre tégula y con la abreviatura L(egio) VII G(emina) P(ia), que se va a convertir en el modelo estándar para el siglo III (Fig. 15). Esta misma marca se ha recuperado en otros materiales de León (García y Bellido, 1970, 593; Amaré y Álvarez Vega, 2006, 726 y 730).

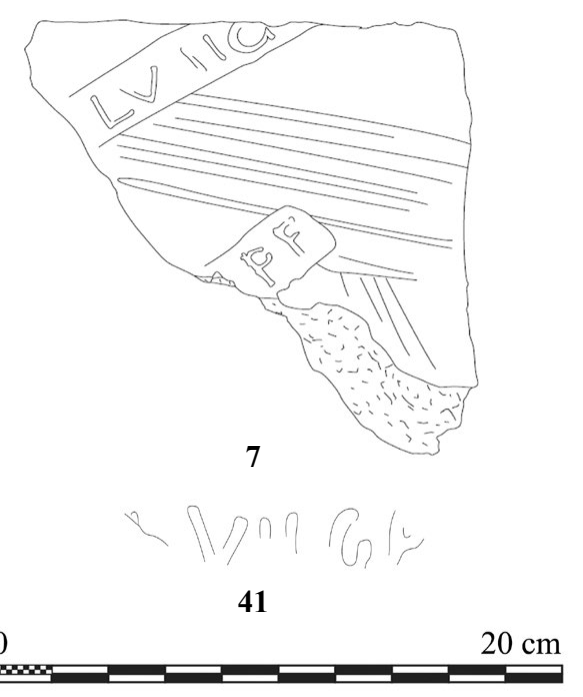

Figura 15: Marcas Legio VII gemina pia $\left(\mathrm{n}^{\circ} 7\right.$ y 41$)$.

\section{LEGIO VII GEMINA PIA FELIX}

García y Bellido indica la existencia de solamente dos únicos casos en que el epíteto pia aparece con el de gemina antepuesto y seguido del de felix (García y Bellido, 1970, 593-94), a los que debemos añadir algunos ejemplares publicados recientemente (Liz Guiral 
y Amaré, 1993, 54; Amaré y Álvarez Vega, 2006, 726 y 730; González Fernández, 1994, 116). En Puerta Obispo documentamos dos fragmentos de tégula $\left(\mathrm{n}^{\circ}\right.$ 43 y 76) y uno de ladrillo ( $n^{\circ} 7$ ) (Fig. 16). En todos los casos la abreviatura será L(egio) VII G(emina) P(ia) $\mathrm{F}(\mathrm{elix})$.

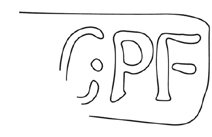

43

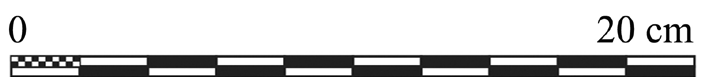

Figura 16: Marcas Legio VII gemina pia felix ( $n^{\circ} 43$ y 76).

\section{LEGIO VII GEMINA ANTONINIANA PIA FELIX}

A partir del gobierno del emperador Caracalla, la legio VII gemina recibe el apelativo de Antoniniana. En este momento se inicia la costumbre de asignar epítetos personales de los emperadores a las unidades militares (Fitz, 1983). Esta designación la hallamos también en lápidas (García y Bellido, 1970, 594). En todos los sellos la F va detrás de la P. El cognomen Antoniniana se abrevia indistintamente como A y a veces en AN (Liz Guiral y Amaré, 1993, 54; Amaré y Álvarez Vega, 2006, 726 y 730; González Fernández, 1994, 116). Dos ejemplares procedentes de las intervenciones en Puerta Obispo presentan esta marca, dispuesta sobre una tégula y una ímbrice (Fig. 17).



63

$$
0
$$

$20 \mathrm{~cm}$

Figura 17: Marca Legio VII gemina Antoniniana pia felix $\left(\mathrm{n}^{\circ}\right.$ $63)$.

\section{LEGIO VII GEMINA MAXIMINIANA PIA FELIX}

Esta marca parece también minoritaria. Hasta el momento sólo se han dado a conocer tres marcas de este tipo (García y Bellido, 1970, 595; Amaré y Álvarez Vega, 2006, 730), a las que debemos sumar la estampilla sobre ladrillo ( $\left.\mathrm{n}^{\circ} 9\right)$ y sobre tegula $\left(\mathrm{n}^{\circ} 54\right)$ que aquí presentamos. Se abrevia como L(egio) VII g(emina) Max(iminiana) p(ia) f(elix) (Fig. 18).

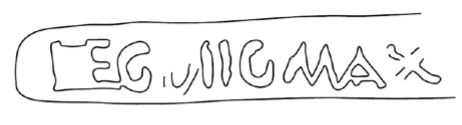

54

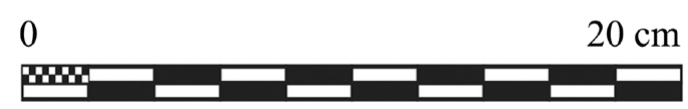

Figura 18: Marca Legio VII gemina Maximiniana pia felix $\left(\mathrm{n}^{\circ}\right.$ $54)$.

\section{LEGIO VII GEMINA GORDIANA PIA FELIX}

Esta marca ha de datarse entre el 238 y 244, fechas del gobierno de Gordiano III. Son relativamente numerosos los sellos con tal leyenda. La abreviatura es muy semejante a la de los sellos anteriores, con el cognomen Gordiana delante de p(ia) f(elix). Como rasgo epigráfico diferenciado debemos mencionar la presencia de interpunciones. En Puerta Obispo se han documentado nueve ejemplares sobre ladrillo $\left(n^{\circ} 8\right)$, tégula (n $39,45,48,50,56,59,64$ y 65). La abundancia de esta marca se ha constatado en publicaciones anteriores sobre el campamento de León (García y Bellido, 1970, 595; Liz Guiral y Amaré, 1993, 55; Amaré y Álvarez Vega, 2006, 730; González Fernández, 1994, 116) (Fig. 19).

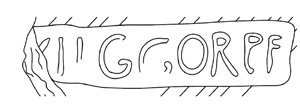

45

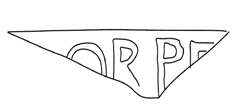

56

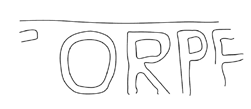

48

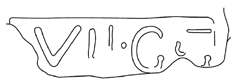

59

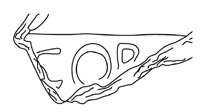

50

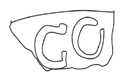

64
0

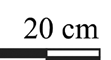

Figura 19: Marcas Legio VII gemina Gordiana pia felix $\left(\mathrm{n}^{\circ} 45\right.$, $48,50,56,59$ y 64$)$.

\section{Legio VII gemina PhilipPiana PIA FELIX}

Estas estampillas, con la abreviatura L(egio) VII G(emina) Phil(ippiana) P(ia) F(elix), se datan entre el 244 y el 249 d. C. y se conocen sobre ladrillos y tégulas (García y Bellido, 1970, 596; Liz Guiral y Amaré, 1993, 55; Amaré y Álvarez Vega, 2006, 730). Cuatro ejemplares más se han hallado en Puerta Obispo (Fig. 20).

Ya hemos señalado más arriba la dificultad que existe para correlacionar cada una de estas marcas con fases edilicias del campamento legionario. Las 




10

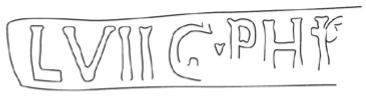

49

0

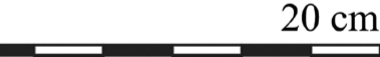

Figura 20: Marcas Legio VII gemina Philippiana pia felix $\left(\mathrm{n}^{\circ}\right.$ 10 y 49$)$.

unidades estratigráficas de las que proceden son en su mayoría niveles de relleno bajoimperiales o tardoantiguos, donde se han amortizado antiguos materiales constructivos altoimperiales. Mientras no podamos obtener datos cronoestratigráficos fiables para el material latericio en contextos altoimperiales indiscutibles, tendremos que seguir remitiéndonos a las dataciones a partir de los epítetos militares presentes en los sellos.

Junto a las estampillas militares propiamente dichas, han llegado hasta nosotros varias marcas de producción realizadas con los dedos, seguramente practicadas por diferentes operarios para contabilizar las piezas elaboradas por cada uno (Brodribb, 1987, 99105). Se constata la presencia de círculos $\left(n^{\circ} 43\right.$ y 62), aspas $\left(n^{\circ} 3\right)$, ondulaciones $\left(n^{\circ} 35\right)$ y líneas rectas $\left(n^{\circ} 57\right.$ y 81 ), sobre tejas y ladrillos.

Uno de los ladrillos presenta el numeral VI escrito con un punzón a mano alzada $\left(\mathrm{n}^{\mathrm{o}} 4\right)$. Teniendo en cuenta que nos encontramos ante un ladrillo de tipo pedal, modalidad que suele emplearse como basa o capitel de las pilae del hipocausto, tal vez se trataría de un indicativo del número de la ubicación de la pila correspondiente.

También se han localizado improntas de huellas humanas y animales realizadas sobre lateres y tegulae antes de su cocción, cuando la arcilla estaba todavía fresca en la era de secado (Brodribb, 1987, 125-127). Entre ellas destacan las impresiones de suelas de sandalias o botas claveteadas (caligae, calcei), cuya presencia en León ya fue apuntada por García y Bellido (García y Bellido, 1970, Figs. 83-85), quien documenta dos improntas de caligae de adultos y una infantil (carbatina). Este calzado es característico de soldados y trabajadores e ilustra muy bien sobre la condición del personal de las tegulariae. Una huella del mismo tipo apareció en el fuerte romano de Cidadela (Carlsson-Brandt, 2011, 172, Fig. 6, 7).

En las excavaciones de Puerta Obispo se ha documentado una nueva impronta de caliga $\left(\mathrm{n}^{\circ} 6\right)$, que en realidad es una doble pisada superpuesta parcialmente en la zona del talón, donde coincide con la parte delantera de una pisada posterior. En la parte anterior se observa el talón claveteado de otra huella. En realidad estamos ante un ladrillo sobre el que se ha pisado en dos ocasiones diferentes, probablemente la misma persona. Según la tipología de calzado propuesta por Van Driel Murray (2001, 350-351), a partir de la forma (tipo 2) y la disposición de las tachuelas impresas en el ladrillo, que responden a su tipo 3 , podríamos datar la caliga en un momento comprendido entre finales del siglo I y la primera mitad del siglo II d. C.

También se conservan huellas de tres cánidos, posiblemente perros (canis familiaris) ( $\mathrm{n}^{\mathrm{o}}$ 6, 37 y 38), que se enmarcan dentro de las abundantes huellas de animales sobre material latericio (perro, gato, oveja, cabra, caballo, cerdo, vaca, zorro, lobo, aves, etc.) (Brodribb, 1987, 125-127; Forest, 2011, 299-301). Se ha señalado la llamativa abundancia de huellas de zorro (Bermúdez, 1987, 931-932), lo que indica el carácter periurbano de las officinae latericias. Tal y como ya han apuntado algunos autores (Sarnowski, 1983), no parece lógica la hipótesis de Spitzlberger sobre el carácter apotropaico de las huellas de animales sobre material latericio $(1968,88)$.

\section{CONSIDERACIONES FINALES}

Las intervenciones realizadas en el sector de Puerta Obispo de la ciudad de León durante 1996 permitieron conocer mejor el sector oriental del campamento flavio de la legio VII gemina, localizando la antigua porta principalis sinistra del recinto militar, así como parte de la via sagularis y la esquina de una gran manzana ocupada por las termas legionarias, que se encuentran bajo la actual catedral (García Marcos et alii, 2004; Morillo y García Marcos, 2005), en la que se documentan varias fases constructivas, la última de las cuales corresponde a unas letrinas romanas.

Las excavaciones han proporcionado un interesante conjunto latericio que hemos presentado en estas páginas, que se eleva a más de 300 piezas. Entre estos materiales se constata la presencia de ladrillos del tipo bessal y pedal, pertenecientes a hipocaustos, tejas (tegulae e imbrices), suelos (opus spicatum) y elementos vinculados a concamerationes (tegulae mammatae y tubuli), pertenecientes a los pavimentos, paredes y techumbres de los edificios exhumados.

Tan sólo los ladrillos para pavimentos (opus spicatum), que solaban un espacio destinado en origen a una posible piscina, se han hallado en posición primaria, aunque muchos de ellos se encontraron fuera de su ubicación original, o bien se recogieron durante las labores de limpieza y la posterior adecuación museográfica. El resto de los materiales aparece reutilizado en fases constructivas posteriores o formando parte de paquetes estratigráficos de rellenos o aterrazamiento de época bajoimperial o tardoantigua. Este hecho limita sensiblemente no sólo nuestra capacidad para determinar su procedencia original, sino también el establecimiento de marcos temporales precisos. El registro estratigráfico confirma que las letrinas son desmanteladas a partir de mediados del siglo III. A finales de esta misma centuria, en correlación con la edificación 
de la muralla bajoimperial, la puerta romana sufre diversas reformas, entre las que se encuentran el cierre del vano septentrional de la misma y el recrecimiento del suelo del cuerpo de guardia, para lo que se emplearon restos de materiales latericios procedentes de la techumbre.

Teniendo en cuenta la tipología de los elementos recuperados, entre los que abundan los que formaron parte de estancias calefactadas (hypocausta, concamerationes, tejas-tragaluz), consideramos que el lugar de procedencia de la mayor parte de dichos materiales debe ser el vecino edificio termal. El sistema de hipocausto propio de los baños romanos exige el empleo de material latericio de tipometría muy diversa, que por las cualidades físicas de la arcilla cocida soporta altas temperaturas y es un buen conductor del calor generado en los praefurnia. Su plasticidad permite adaptarlo además a cualquier tipo de estancia calefactada, con sólo modificar su tamaño y morfología, aplicándose tanto a la construcción del hipocausto propiamente dicho como a las concamerationes o dobles paredes. Junto al material creado específicamente para las estancias calientes, en los edificios termales se emplean también ladrillos para las paredes y obras de infraestructura y canalización, así como tejas de diferente morfología (tegulae e imbrices) para los tejados.

Las procedencia de buena parte de los materiales latericios de estancias termales se ve confirmada por la presencia en los mismos estratos de restos de pavimentos musivos, decoración arquitectónica y parietal, así como revestimientos y restos de mobiliario marmóreo recuperados como un gran labrum, alguno de los cuales hemos dado a conocer recientemente (Morillo y Salido; 2010, 2011). Dichos materiales se concentran principalmente en la zona de las letrinas. Por el contrario, en las calles y el cuerpo de guardia de la puerta romana se identifican casi exclusivamente tegulas e imbrices en estado fragmentario, que deben responder a reformas en la porta principalis sinistra.

La publicación, hace algunos años, de la producción latericia completa de determinados alfares hispanos meridionales (Torrecilla, 1998; Redondo y Borge, 1998), nos permite plantear que la totalidad, o la inmensa mayoría de los ejemplares aquí presentados, independientemente de su tipología o que presenten o no la marca militar, fueron elaborados en los alfares destinados por la legio VII gemina a la fabricación de material constructivo, apenas conocidos en la actualidad (Gutiérrez González, 1985, 156-159).

El hecho de que dicho material esté en su inmensa mayoría sellado constituye un rasgo peculiar de la capital leonesa. Hemos constatado un amplio repertorio de marcas militares de la legio VII gemina, todas ellas ya documentadas, cuyo ámbito temporal se extiende entre el periodo flavio y mediados del siglo III d. C. Teniendo en cuenta las limitaciones estratigráficas no hemos podido ir más allá de la datación propuesta en su día por García y Bellido a partir de los epítetos militares que figuran en cada una. Se han identificado también marcas de producción, numerales e improntas de calzado y huellas animales que nos informan sobre aspectos productivos y de la vida cotidiana en el campamento de la legio VII gemina.

Prof. Dr. Ángel Morillo Cerdán
Departamento de Ciencias y Técnicas
Historiográficas y de Arqueología
Facultad de Geografía e Historia
C/ Profesor Aranguren, s/n
Universidad Complutense
Ciudad Universitaria
28040 Madrid
amorillo@ghis.ucm.es
Javier Salido Domínguez
Escuela Española de Historia y
Arqueología en Roma-CSIC
Via di Torre Argentina 18
00186 Roma
salido@csic.it

\section{BIBLIOGRAFÍA}

ABASCAL PALAZÓN, J. M., 1986: «La Legio VII Gemina. Balance de la investigación y perspectivas», I Congreso Internacional Astorga Romana, I, 317-328, Astorga.

ABASCAL PALAZÓN, J. M., 2010: «Nuevas marcas sobre tégulas romanas en enclaves de la Costa de Alicante (Hispania Citerior)», Lucentum, 28, 183-192.

ABASCAL PALAZÓN, J. M., RIQUELME, T. y CEBRIÁN FERNÁNDEZ, R., 2000: «Retucenus Elocum, Turanus, Artirus y la producción de tegulae en Segobriga», Anales de Prehistoria y Arqueología, 16, 187-197.

ADAM, J.-P., 1996: La construcción romana: Materiales y técnicas, León.

AMARÉ TAFALLA, M ${ }^{\mathrm{a}}$ T. y ÁLVAREZ VEGA, E., 2006: «Material latericio de la legio VII procedente del polígono de La Palomera (León)», en A. MORILLO (Ed.), Arqueología Militar Romana en Hispania. Producción y abastecimiento en el ámbito militar, 725-732, León.

BELTRÁN LLORÍS, M. y PAZ PERALTA, J. A (Coords.), 2004: Las aguas sagradas del municipium Turiaso. Excavaciones en el Patio del Colegio Joaquín Costa (antiguo Allué Salvador). Tarazona (Zaragoza), Caesaraugusta, 76, Zaragoza.

BENDALA GALÁN, M., RICO, Ch. y ROLDÁN GÓMEZ, L. (Eds.), 1999: El ladrillo y sus derivados en la época romana, Madrid.

BENDALA GALÁN, M. y ROLDÁN GÓMEZ, L., 1999:«El cambio tecnológico en la arquitectura hispanorromana: perduraciones, novedades, particularidades», en R. de BALBIN y P. BUENO (eds.), II Congreso de Arqueología Peninsular, IV, 103-116, Alcalá de Henares.

BENOIT, F., 1977: Cimiez, La Ville antique (Monuments, Histoire), Fouilles de Cemenelum, I, París.

BERMÚDEZ, A., 1985: Introducción al estudio del material de construcción de tipo cerámico en la arquitectura romana de Tarraco: clasificación y análisis de las tégulas e ímbrices depositadas en el Museo Paleocristiano de Tarragona, Tesis de licenciatura inédita. 
BERMÚDEZ, A., 1987: «Interés, problemática y metodología del estudio de material de construcción de tipo cerámico en la arquitectura romana de Tarraco», Congreso Nacional de Arqueología XVIII, 923-932, Zaragoza.

BLOCH, H., 1938: I bolli laterizi e la storia edilizia romana, Roma.

BLOCH, H., 1967: The roman brick stamps, Roma.

BOON, G. C., 1984: Laterarium Iscanum. The antefices, bricks and stamps of the Second Augustan Legion, Cardiff.

BOUET, A., 1999: Les matériaux de construction en terre cuite dans les thermes de la Gaule Narbonnaise, Bordeaux.

BRODRIBB, G., 1987: Roman Brick and Tile, Gloucester.

BRUUN, Ch. (Ed.), 2005: Interpretare $i$ bolli laterizi di Roma e della Valle del Tevere: Produzione, storia economica et topografia, Acta Instituti Romani Finlandiae, 32, Roma.

BRUUN, Ch., 2005b: «La ricerca sui bolli laterizi praesentazione generale delle varie problematiche», en Ch. BRUUN (Ed.), Interpretare i bolli laterizi di Roma e della Valle del Tevere: Produzione, storia economica et topografia, Acta Instituti Romani Finlandiae 32, 3-24, Roma.

CAMPOMANES, E., 2006: «El acueducto de la legio VII gemina y sus producciones latericias», en A. MORILLO (Ed.), Arqueología Militar Romana en Hispania. Producción y abastecimiento en el ámbito militar, 439-454, León.

CARLSSON-BRANDT FONTÁN, E., 2011: «El material constructivo latericio en el campamento romano de Cidadela (Sobrado do Monxes, A Coruña)», Gallaecia, 30, 167-180.

CEBRIÁN FERNÁNDEZ, R., 2010: «La producción latericia en Segobriga: nuevos hallazgos (2002-2009)», Lucentum, 18, 169-182.

DARVILL, T. y McWHIRR, A., 1984: «Brick and tile production in Roman Britain. Models of economic organisation», World Archaeology, 15, 239-261.

DEGBOMONT, J.-M., 1984: Le chauffage par hypocauste dans l'habitat privé. De la place St-Lambert à Liège à $l^{\prime}$ Aula Palatina de Trèves, $2^{\mathrm{e}}$ edition, Liège.

VAN DRIEL MURRAY, C., 2001: «Footwear in the NorthWestern Provinces of the Roman Empire», en O. GOUBITZ, C. van DRIEL-MURRAY y W. GROENMANVAN WAATERINGE (Eds.), Stepping Through Time. Archaeological Footwear from Prehistoric Times until 1800, 337-376.

DURÁN CABELLO, R.-M., 1998: La última etapa del teatro romano de Mérida. La uersura oriental y los sellos latericios, Cuadernos Emeritenses, 14, Mérida.

DURÁN CABELLO, R.-M., 1999: «El uso del ladrillo en la arquitectura de Augusta Emerita», en M. BENDALA GALÁN, Ch. RICO y L. ROLDÁN GÓMEZ (Eds.), El ladrillo y sus derivados en la época romana, 205-220, Madrid.

FERNÁNDEZ OCHOA, C., MORILLO, A. y SALIDO DOMÍNGUEZ, J., 2011: «Ciudades amuralladas y annona militaris durante el Bajo Imperio en Hispania: una cuestión a debate», en J. ARCE y B. GOFFAUX (Eds.), Horrea d'Hispanie et de la Méditerranée Romaine, 265285, Madrid.

FERNÁNDEZ OCHOA, C. y ZARZALEJOS, M., 1996: «Técnicas constructivas en las termas romanas de Campo Valdés (Gijón): el material latericio», Archivo Español de Arqueología, 69, 109-118.

FERNÁNDEZ OCHOA, C., MORILLO, A. y ZARZALEJOS, M., 1999: «Material latericio en las termas romanas de Hispania», en M. BENDALA GALÁN, Ch. RICO y L. ROLDÁN GÓMEZ (Eds.), El ladrillo y sus derivados en la época romana, 291-305, Madrid.

FERNÁNDEZ FREILE, B. E., 2003: La época romana en León. Aspectos arqueológicos. Estudio arqueológico de un vertedero romano situado en la calle Maestro Copín c/v San Salvador del Nido en la ciudad de León, León.

FERNÁNDEZ VEGA, P. A., RAMOS SAINZ, M. L. y RUIZ GUTIÉRREZ, A., 2009: «Marcas de fábrica sobre material de construcción cerámico en la Cantabria romana», Sautuola, XV, 299-309.

FITZ, J., 1983: Honorific titles of Roman military units in the 3rd century, Budapest.

FOREST, V., 2011: «Annexe. Étude des empreintes d'animaux sur les matériaux de construction», en A. BOUET (Ed.), Barzan, III: Un secteur d'habitat dans le quartier du sanctuaire du Moulin du Fâ à Barzan (Charente-Maritime), 299-301, Bordeaux.

GARCÍA Y BELLIDO, A., 1970: «Estudios sobre la Legio VII Gemina y su campamento en León», Legio VII Gemina, 569-599, León.

GARCÍA MARCOS, V., 2002: «Novedades acerca de los campamentos romanos de León», en A. MORILLO (Coord.), Arqueología Militar Romana en Hispania, Anejos de Gladius 5, 167-21, Madrid 2.

GARCÍA MARCOS, V., CAMPOMANES, E. y MIGUEL HERNÁNDEZ, F., 2004: «El solar y el entorno urbano de Santa María de Regla (ss. I-XV)», en J. YARZA, M V. HERRAEZ y G. BOTO (Eds.), Congreso Internacional: La Catedral de León en la Edad Media, 23-44, León.

GISBERT, J. A., 1999: «El alfar de L'Amadrava (Setla-Mirarosa-Miraflor)-Dianium-. Materiales de construcción cerámicos. Producción y aproximación a su funcionalidad en la arquitectura del complejo artesanal», en M. BENDALA GALÁN, Ch. RICO y L. ROLDÁN GÓMEZ (Eds.), El ladrillo y sus derivados en la época romana, 65-102, Madrid.

GONZÁLEZ, M., 1981: «Gran noticia arqueológica en el valle de Fenar», Revista de León 327-329, 15-17.

GONZÁLEZ FERNÁNDEZ, Mª L., 1994: «Necrópolis Tardorromana en el solar del Monasterio de San Claudio de León», Nvmantia, 5, 107-126.

GUDEA, N., 1978: «Descoperiri archeologice si epigrafice mai vechi sau mai noi Porolissum», Acta Musei Porolissensis, II, 65-75.

GUTIÉRREZ GONZÁLEZ, A., 1985: Poblamiento antiguo y medieval en la Montaña central leonesa, León.

HELEN, T., 1975: Organization of Roman Brick Production in the first and second centuries AD: An interpretation of Roman Bricks Stamps, Helsinki. 
KURZMANN, R., 2006: Roman military brick stamps: A comparison of Methodology, BAR Int. Series, 1543, Oxford.

LE BOHEC, Y., 1992: «Les estampilles de l'armée romaine sur briques et sur tuiles», Epigraphica, 54, 43-62.

LE ROUX, P., 1981: «Inscriptions militaires et déplacements de troupes dans l'Empire romain», ZPE, 43, 119-200.

LE ROUX, P., 1982: L'armée romaine et l'organisation des provinces ibériques d'Auguste a l'invasion de 409, Paris.

LE ROUX, P., 1999: «Briques et tuiles militaires dans la Péninsule Ibérique: problèmes de production et de diffusion», en M. BENDALA GALÁN, Ch. RICO y L. ROLDÁN GÓMEZ (Eds.), El ladrillo y sus derivados en la época romana, 111-124, Madrid.

LIZ GUIRAL, J. y AMARÉ TAFALLA, M. T., 1993: Necrópolis tardorromana del Campus de Vegazana, León.

LUDOWICI, W. 1905: Stempel-Bilder römischer Töpfer: aus meinen Ausgrabungen in Rheinzabern, nebst dem II. Teil der Stempel-Namen 1901-1905, Katalog meiner Ausgrabungen in Rheinzabern 2, Jockgrim.

LUDOWICI, W., 1912: «Truppenziegeleien in Rheinzabern und leg. VII gemina am Rhein», Römische Ziegelgräber: Stempel-Namen, Stempel-Bilder, Urnen-Gräber, Katalog meiner Ausgrabungen in Rheinzabern 19081912, 4, 115-116, München.

MANACORDA, D., 2000: «I diversi significati dei bolli laterizi. Appunti e riflessioni», en P. BOUCHERON, H. BROISE y Y. THÉBERT (Eds.), La brique Antique et médiévale. Production et commercialisation d'un matériau, Actes du colloque international organisé par le Centre d'histoire urbaine de l'École normale supérieure de Fontenay/Saint Cloud et l'École française de Rome, Saint-Cloud, 16-18 novembre 1995, 127-159, Roma.

MANACORDA, D., 2005: «Appunti sull'industria edilizia a Roma», en Ch. BRUUN (Ed.), Interpretare $i$ bolli laterizi di Roma e della Valle del Tevere: Produzione, storia economica et topografia, Acta Instituti Romani Finlandiae 32, 25-52, Roma.

MARTÍN VALLS, R., ROMERO CARNICERO, M ${ }^{\mathrm{a}}$ V. y CARRETERO, S., 2002: «Marcas militares en material de construcción de Petavonium», en A. MORILLO (Coord.), Arqueología Militar Romana en Hispania, Anejos de Gladius 5, 137-154, Madrid.

McWHIRR, A., (Ed.) 1979: Roman Brick and Tile. Studies in Manufacture, Distribution and Use in the Western Empire, BAR International Series, 68, Oxford.

MORILLO, A., 2005: «Hispania en la estrategia militar del Alto Imperio: movimientos de tropa en el Arco Atlántico a través de los testimonios arqueológicos», en C. FERNÁNDEZ OCHOA y P. GARCÍA DÍAZ (Eds.), III Coloquio Internacional de Arqueología en Gijón. Unidady diversidad en el Arco Atlántico en época romana, BAR Int. Series, 1371, 19-33, Oxford.

MORILLO, A., 2008: «Producciones cerámicas militares en Hispania», en D. BERNAL y A. RIBERA (Eds.), Cerámicas hispanorromanas. Un estado de la cuestión, $165-$ 184, Cádiz.
MORILLO, A., 2012: «Investigación científica y arqueología urbana en la ciudad de León», en J. BELTRÁN y O. RODRÍGUEZ (Eds.), Hispaniae urbes. Investigaciones arqueológicas en ciudades históricas, Sevilla, en prensa.

MORILLO, A. y GARCÍA MARCOS, V., 2003: «Legio VII Gemina and its Flavian fortress at León», JRA, 16, 275-286.

MORILLO, A. y GARCÍA MARCOS, V., 2005: «The defensive system of the legionary fortress of VII gemina at León (Spain). The porta principalis sinistra», en Z. VISY (Ed.), Limes XIX. Proceedings of the XIXth International Congress of Roman Frontier Studies (2003), 569-583, Pécs.

MORILLO, A. y GARCÍA MARCOS, V., 2006: «Legio (León). Introducción histórica y arqueológica», en $\mathrm{M}^{\mathrm{a}} \mathrm{P}$. GARCÍA-BELLIDO (Coord.), Los campamentos romanos en Hispania (27 a. C.-192 d. C.). El abastecimiento de moneda, Anejos de Gladius 9, 225-243, Madrid.

MORILLO, A. y GÓMEZ BARREIRO, M., 2006: «Circulación monetaria en los campamentos romanos de León», en $\mathrm{M}^{\mathrm{a}}$ P. GARCÍA-BELLIDO (Coord.), Los campamentos romanos en Hispania (27 a. C.-192 d. C.). El abastecimiento de moneda, Anejos de Gladius 9, 258291, Madrid.

MORILLO, A. y SALIDO DOMÍNGUEZ, J., 2010: «Labrum procedente de las termas del campamento de la legio VII gemina en León», Zephyrus, LXV, 167-178.

MORILLO, A. y SALIDO DOMÍNGUEZ, J., 2011: «Decoración arquitectónica del campamento de la legio VII gemina en León», Cuadernos de Prehistoria y Arqueología de la Universidad Autónoma de Madrid, 37, $37-$ 38, 599-623.

MORILLO, A. y SALIDO DOMÍNGUEZ, J., e.p.: «Marcas militares sobre producciones latericias en Hispania. Nuevas consideraciones sobre su origen y difusión», Gerión, en prensa.

PALAO, J. J., 2006: Legio VII Gemina (Pia) Felix. Estudio de una legión romana, Salamanca.

PALAO, J. J., 2010: «On the concession of the title "Felix" to Legio VII Gemina», Athenaeum, 90, II, 437-444.

PEACOCK, D. P. S., 1982: Pottery in the Roman world: an ethnoarchaeological report, London y New York.

PÉREZ GONZÁLEZ, C., 1989: Cerámica romana de Herrera de Pisuerga (Palencia, España). La terra sigillata, Santiago de Chile.

PIZZO, A., 2010: «El opus testaceum en la arquitectura pública de Augusta Emerita», Archivo Español de Arqueología, 83, 147-174.

DE POORTER, A. y CLAEYS, P.-J., 1989: Les sigles sur matériaux de construction romains en terre cuite en Belgique, Acta archaeologica Lovaniensia, Monographiae, 1, Leuven.

RICO, Ch. 1995: «Índex de les marques epigràfiques sobre tegulae romanes de Catalunya i el País Valencià (antiga Tarraconensis)», Saguntum, 28, 197-216.

RICO, Ch., 1999: «Éléments pour une aproche socio-économique de la production de matériaux de construction en terre cuite dans les provinces hispaniques», en M. BENDALA GALÁN, Ch. RICO y L. ROLDÁN GÓMEZ 
(Eds.), El ladrillo y sus derivados en la época romana, 25-44, Madrid.

RICO, Ch., 2000: «La production de briques et de tuiles dans la province romaine de Bétique. L'exemple de la vallée du Guadalquivir», en P. BOUCHERON, H. BROISE y Y. THÉBERT (Eds.), La brique Antique et médiévale. Production et commercialisation d'un matériau, Actes du colloque international organisé par le Centre d'histoire urbaine de l'École normale supériure de Fontenay/Saint Cloud et l'École française de Rome, Saint-Cloud, 16-18 novembre 1995, 177-192, Roma.

ROLDAN, J. M., 1974: Hispania y el ejército romano, Salamanca.

ROLDÁN GÓMEZ, L., 1992: Técnicas constructivas romanas en Carteia, Monografías de Arquitectura romana, 1, Madrid.

ROLDÁN GÓMEZ, L., 1993: Técnicas constructivas romanas en Italica, Monografías de Arquitectura romana, 2, Madrid.

ROLDÁN GÓMEZ, L., 1995: «Aspects constructifs des thermes romains de la Baetica», L'Africa romana. Atti dell'XI Convegno di studio, 789-821, Sassari.

ROLDÁN GÓMEZ, L., 1999: «Arquitectura pública en las ciudades de la Bética. El uso del opus testaceum», en M. BENDALA GALÁN, Ch. RICO y L. ROLDÁN GÓMEZ (Eds.), El ladrillo y sus derivados en la época romana, 179-204, Madrid.
ROLDÁN GÓMEZ, L., 2008: «El material constructivo latericio en Hispania. Estado de la cuestión», en D. BERNAL y A. RIBERA (Eds.), Cerámicas Hispanorromanas. Un estado de la cuestión, 749-773, Cádiz.

SETÄLÄ, P., 1977: Private domini in Roman brick stamps of the Empire. A historical and prosopographical study of landowners in the district of Rome, Annales Academiae Scientiarum Fennicae. Dissertationes humanarum litterarum, 10, Helsinki.

SARNOWSKI, T., 1983: «Die Ziegelstempel aus Novae», Archeologia Warszawa, 43, 17-61.

SPITZLBERGER, G., 1968: «Die römischen Ziegelstempel im nördlichen Teil der Provinz Raetien», Saalburg Jahrbuch, 25, 65-184.

STEINBY, E. M., 1974-75: «La cronologia delle figlinae doliari urbane dalla fine del'età repubblicana fino all'inizio del III sec.», Bullettino della Commissione archeologica comunale di Roma, 84, 7-132.

STEINBY, E. M., 1999: «Ricerca sui personaggi dei bolli laterizi di Roma», en M. BENDALA GALÁN, Ch. RICO y L. ROLDÁN GÓMEZ (Eds.), El ladrillo y sus derivados en la época romana, 103-110, Madrid.

SZILAGYI, J., 1972: «Ziegelstempel», RE XA, 2.19, 433-446.

WARRY, P., 2006: Tegulae. Manufacture, tipology and use in Roman Britain, BAR British Series, 417, Oxford.

WARRY, P., 2006b: «A dated typology for Roman roof-tiles (tegulae)», AJA, 19, 247-265.

Recepción: 17-01-2013

Aceptación: 26-08-2013 